Portland State University

PDXScholar

\title{
A Comparison of the Expressive Speech of Profoundly Hearing-Impaired Children : "Hearing Aids On" Versus "Hearing Aids Off"
}

James Allen Henry

Portland State University

Follow this and additional works at: https://pdxscholar.library.pdx.edu/open_access_etds

Part of the Speech Pathology and Audiology Commons

Let us know how access to this document benefits you.

\section{Recommended Citation}

Henry, James Allen, "A Comparison of the Expressive Speech of Profoundly Hearing-Impaired Children : "Hearing Aids On" Versus "Hearing Aids Off"'" (1987). Dissertations and Theses. Paper 3714. https://doi.org/10.15760/etd.5598

This Thesis is brought to you for free and open access. It has been accepted for inclusion in Dissertations and Theses by an authorized administrator of PDXScholar. Please contact us if we can make this document more accessible: pdxscholar@pdx.edu. 
AN ABSTRACT OF THE THESIS OF James Allen Henry for the Master of Science in Speech Communication: Emphasis in Speech Pathology/Audiology presented July 16, 1987.

Title: A Comparison of the Expressive Speech of Profoundly Hearing-Impaired Children: "Hearing Aids On" versus "Hearing Aids Off."

APPROVED BY MEMBERS OF THE THESIS COMMITTEE:

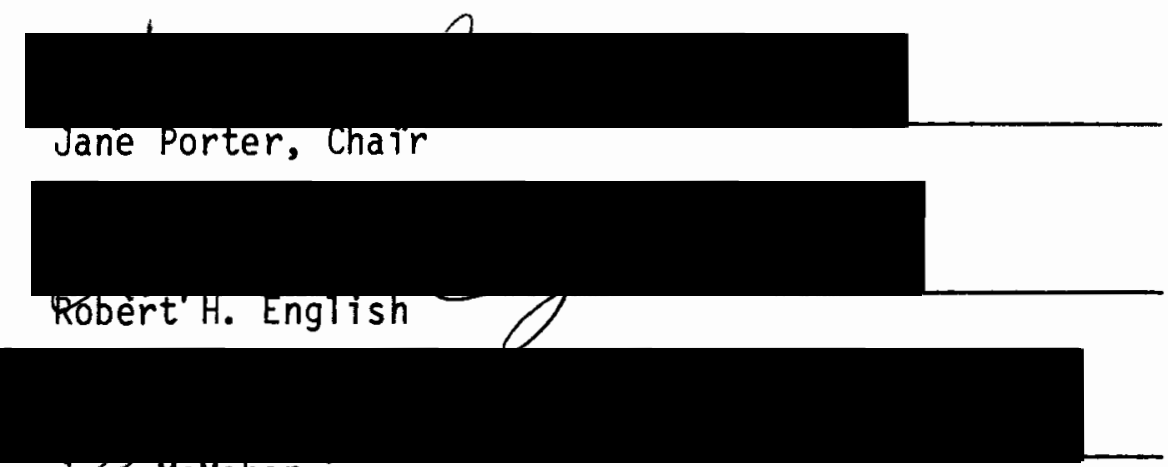

Joan Mclmahon

Profoundly hearing-impaired children who are educated in an oral environment acquire dependence on hearing aids for auditory reception of speech. While it is commoniy accepted that these children's receptive auditory abilities are reduced when amplification is removed, it is not known whether their expressive speech abilities are impaired with the removal of amplification.

This investigation was conducted to determine whether the removal of hearing aids from these children for eighteen hours $1 \pm 1 / 2$ hour and including sleep time) would result in reduced speech 
intelligibility as perceived by a panel of listening judges who were unfamiliar with the speech of the deaf.

Ten profoundly hearing-impaired students, 8 to 13 years of age, were selected from an oral school for the deaf. Their speech was sampled one day with hearing aids on, and the next day with hearing aids off. The speech samples were dubbed onto a master listening tape in blind random order to allow the direct comparison of each sentence in the "Aided" condition to the same sentence in the "Unaided" condition, without listener knowledge of the condition of each sentence.

A panel of 63 judges listened to the master tape and made judgments, for each sentence pair, between: 1) "Sentence \#1 Most Intelligible;" 2) "Sentence \#2 Most Intelligible;" or 3) "No Difference in Intelligibility."

Results indicated that the judges chose the "Hearing Aids On" condition as "Most Intelligible" significantly more often than the "Hearing Aids Off" condition. These results may be confounded, however, by a "repetition of utterance" effect whereby the judges chose the second sentence in each sentence pair as "Most Intelligible" significantly more often than the first sentence. It remains for future studies to verify or refute the results of this study, but "repetition of utterance" effect aside, the judges in this study significantly found the speakers to be more intelligible with amplification than without for the specified time period. 
A COMPARISON OF THE EXPRESSIVE SPEECH OF PROFOUNDLY HEARING-IMPAIRED CHILDREN: "HEARING AIDS ON" VERSUS "HEARING AIDS OFF"

by

JAMES ALLEN HENRY

A thesis submitted in partial fulfillment of the requirements for the degree of

\author{
MASTER OF SCIENCE \\ in \\ SPEECH COMMUNICATION: EMPHASIS IN \\ SPEECH PATHOLOGY/AUDIOLOGY
}

Portland State University 
TO THE OFF ICE OF GRADUATE STUDIES AND RESEARCH:

The members of the Committee approve the thesis of James Allen Henry presented July 16, 1987.

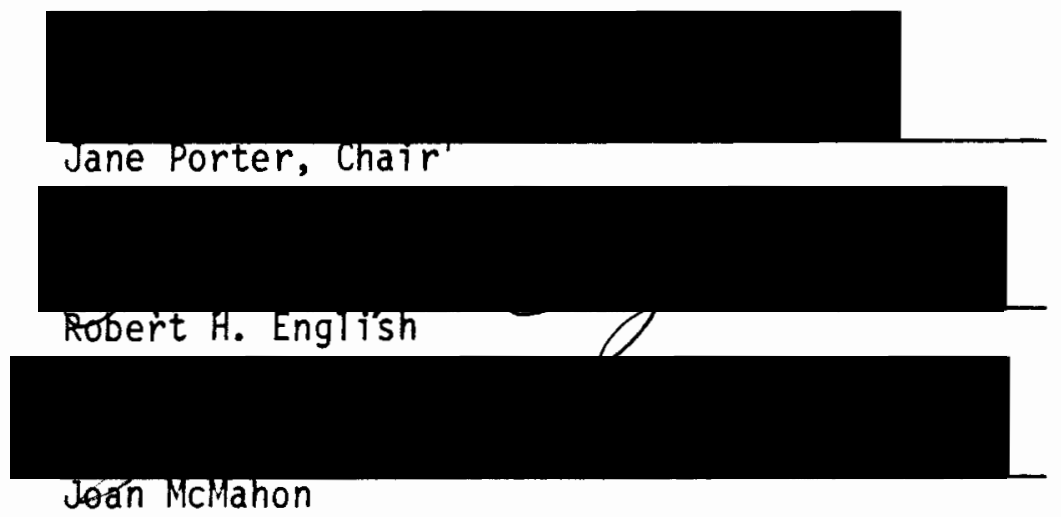

APPROVED:

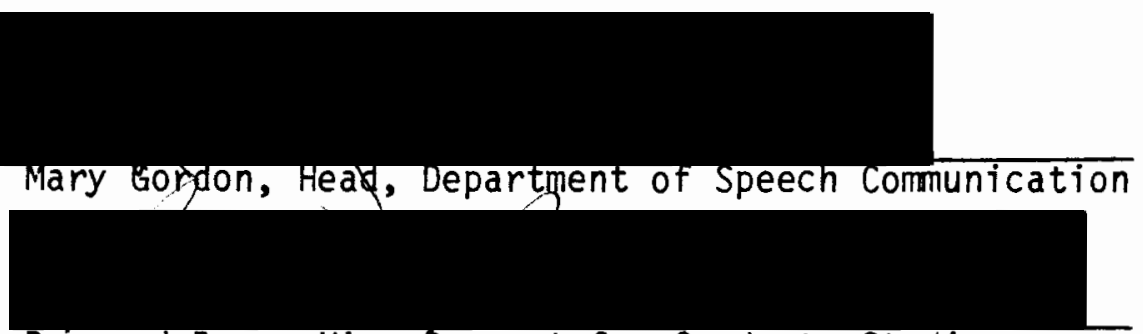

Bernard Ross, Vice-Provost for Graduate Studies 


\section{ACKNOWLEDGMENTS}

There are many persons who have assisted in making this masters thesis a reality. Without their giving participation, it would not have been possible to conduct this study. To Rhea Paul, Ph.D. and Robert Casteel, Ph.D., who team-taught the graduate studies class that provided the original direction for this research, I am grateful. To James Maurer, Ph.D. who initiated the question that this research addressed (in a "brainstorming" session), I express my appreciation. To Jane Porter, M.S., who has been a steady source of guidance and support throughout the project, I am thankful. To Robert English, D.Ed., who gave unselfishly of his time and talents, I am grateful. To Joan McMahon, M.S., who gave "above and beyond," I wish to thank you. To Joseph Langhans, Ph.D., who provided much technical and professional direction during critical periods, I am thankful. To Edith Sullivan, Ph.D., who encouraged me so much during my first year "back to school" and graciously helped me finish this work, I express my thanks and appreciation. Other scholars have also been a source of guidance, direction, and inspiration to myself in various ways that have contributed to the completion of this project. They include Mary Gordon, M.S., Thomas Dolan, Ph.D., John McDermott, Ph.D., Richard Frey, B.S., Steven Fausti, Ph.D., and the late Shari Kazdoy, M.A. The support of many persons in the Portland area has also been invaluable in this endeavor. The staff at the Tucker-Maxon Oral School has been directly involved with the collection of data, and 
their support and encouragement are very much appreciated. They include Patrick Stone, M.S., Arlie Adam, M.S., George Fortier, M.S., Linda Goodwin, M.S., and Dianne Brair, M.S. The students at Tucker-Maxon who provided their oral skills were the crux of the entire project and they, along with their parents (who agreed to the "unheard-of" request of allowing their children to go without hearing aids for a period of time), are al so very much appreciated.

There are many persons who have been a constant source of inspiration and encouragement to me during this time of schooling and preparation for a new career. They have been friends, teachers, schoolmates, and family; all have contributed in their own way towards the completion of this project and the growth of myself as a person. They are too many to name, but I appreciate them all. Finally, I would like to thank my family members at home, who have been very patient and understanding with a Dad (and fiancee) who had to put so much time and energy into shaping a new life. My sincere thanks, love, and appreciation go to Kristin, Erin, and Susan. 
TABLE OF CONTENTS

PAGE

ACKNOWLEDGMENTS

LIST OF TABLES ................... . . vii

CHAPTER

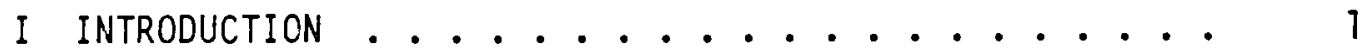

I I REVIEW OF THE LITERATURE ................ 3

Definitions................. 3

Hearing Loss Defined

"Deaf," "Deafness," and "Hearing-Impaired" Defined

"Hard-of-Hearing" Defined

Current Methods of Hearing-Impaired Education

Hearing Loss Population Demographics . . . . .

The Question of How to Best Educate the

Hearing-Impaired Student..........

Manual

Oral

Total Communication

Summary

Comparison of "Aided" and "Unaided" Deaf Speech . . 10

Auditory Feedback .............. . . 11

Attributes of Hearing-Impaired Speech . . . . 12

Overall Attributes of Hearing-Impaired Speech

Specific Attributes of Hearing-Impaired Speech

Listener Judgments of the Speech Intelligibility

of Deaf Children .......... 16

Experienced Versus Inexperienced Listening Judges

Effect of Experience on Inexperienced Listeners 
Speaker and Conditional Variables Affecting Intelligibility Ratings .........

Correlation Between Intelligibility and Hearing Loss

Speech Intelligibility as a Function of Age Complexity of Utterance

Context of Utterance

Repetition of Utterance

Visibility of the Speaker

Interactions Between Different Factors

Affecting Intelligibility

Correlation of Speech Errors and Intelligibility Judgments ............

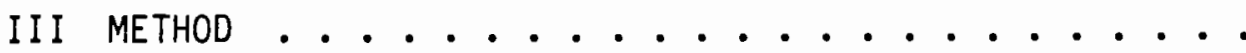

Subjects .................

Procedure ............... . .

Materials

Intelligibility Judgments

Total Listener Decisions: Original Sentences

Statistical Analysis of Data .........

IV RESULTS AND DISCUSSION .................. 35

Results................

Totals: "On" Versus "Off"

"On" Versus "Off" Comparison

Sentence \#1 Versus Sentence \#2 Comparison

"Aids On" in Column 1 Versus "Aids Off" in Column 1 Analysis of Listening Task Per Quarter

Reliability Test

Discussion

$v$ CONCLUSION .............................. 50

Summary .............. 50

Implications .................... 51

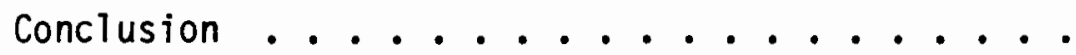


APPENDIX A: CID Everyday Sentences, List B......... 60

APPENDIX B : CID Everyday Sentences, Alternate Sentences . . . 61

APPENDIX C: Instrumentation Technical Data . . . . . . 62

APPENDIX D: Tape-Recorded Instructions to Listening Judges . . 63

APPENDIX E: Scoresheet for Listening Judges . . . . . . . 64

APPENDIX F: Rationale for Use of Chi Square . . . . . . 66

APPENDIX G: Results of Individual Subjects in Order of

Presentation on Listening Tape: "Aids On"

Versus "Aids Off" (Table XIII). .......

APPENDIX H: Results of Individual Subjects in Order of

Presentation on Listening Tape: Sentence \#1

Versus Sentence \#2 (Table XIV). ...... 70

APPENDIX I: Informed Consent Letter: Listening Judges . . . . 71

APPENDIX J: Informed Consent Letter: Parents of Speakers . . . 73

APPENDIX K: Informed Consent Letter: Speakers . . . . . 75 


\section{LIST OF TABLES}

TABLE

PAGE

I Child Subject Information ............ 28

II Comparison of Total Choices for "Hearing Aids On,"

"Hearing Aids Off," and "No Difference in

Intelligibility" . . . . . . . . . . .

II Comparison of Listener Choices Reflecting A Perceived

Difference Between the Two Conditions: "Hearing

Aids On" vs. "Hearing Aids Off" . . . . . . 36

IV Results of Chi Square Analyses for Specific Comparisons 37

$\checkmark$ Comparison of Total Choices: Sentence \#1 Versus

Sentence \#2 .................. 38

VI Comparison of "Hearing Aids On" Choices in Column I Versus

"Hearing Aids Off" Choices in Column 1...... 40

VII Comparison of "Hearing Aids On" in Column 2 to "Hearing

Aids Off" in Column 2 ............

VIII Comparison of Judges' Choices for "On" Versus "Off" Per

Quarter of Listening Task ..........

IX Comparison of Judges' Choices for Sentence \#1 Versus

Sentence \#2 Per Quarter of Listening Task .... .

$X$ Reliability Test: Original Sentences Versus Retest of

Same Sentences in Reverse Order ........

XI Results of Chi Square Analysis of Reliability Test... 
XII Overview of Results of All Comparisons . . . . . . .

XIII Results of Individual Subjects in Order of Presentation on Listening Tape: "Aids On" Versus "Aids Off" . . . . .

XIV Results of Individual Subjects in Order of Presentation on Listening Tape: Sentence \#1 Versus Sentence \#2 . . . 
CHAPTER I

\section{INTRODUCTION}

It is generally recognized that early amplification is essential for hearing-impaired children to take full advantage of their residual hearing and give meaning to the sounds that are available to them (Ling, 1976; Scouten, 1969; Krantz, 1985). Hearing aids make possible auditory training which helps children to recognize the different sounds of speech. While the potential for sound recognition will vary according to many parameters, including degree and configuration of hearing loss, this meaningful auditory information increases receptive communicative abilities (Northern \& Downs, 1984). It is a tedious and lengthy process, but successful oral education programs have demonstrated that through early detection, amplification, and auditory training, with an ongoing program of aural/oral speech and language training, these children can learn to communicate effectively through the world's normal mode which is receptive and expressive oral speech (Ling, 1976).

Acquiring the complex coordinations involved in normal speech production requires the auditory system to be intact, not only to hear how normal speech sounds from others, but also to self-monitor one's own speech productions (Castle, 1970). Hearing aids have become essential to this population in order to utilize their residual hearing for receptive audition, but the effect of the removal of 
amplification on their speech intelligibility has not been determined through research (Stone, 1987).

The purpose of this study was to compare the expressive speech of profoundly hearing-impaired children with "hearing aids on" versus "hearing aids off." Hence, this study sought to answer the following question regarding the expressive speech of profoundly deaf children, ages 8 to 13 years, who have been educated aurally/orally: When these children are dependent upon amplification for speech communication, does the removal of that amplification for a period of 18 hours $1 \pm 1 / 2$ hour and including sleep time) result in reduced speech intelligibility as perceived by the "average listener"? 
CHAPTER II

\section{REVIEW OF THE LITERATURE}

It is the purpose of this chapter to review articles pertinent to the question being asked in this study. Since it is a question that has not been researched up to this time, this review attempts to provide insight gained from other studies which relate to the general task of making intelligibility judgments of hearing-impaired speakers. Additionally, articles are reviewed that pertain to: 1) definitions of terms used throughout this document;2) methods of educating the deaf (as background to understanding the type of educational environment from which the hearing-impaired subjects in this study came); 3 ) auditory feedback (as it relates to the self-monitoring abilities of hearing-impaired persons); and 4) attributes of deaf speech (as a means of understanding the complexities underlying the reduced speech intelligibility of deaf persons).

\section{DEFINITIONS}

The following definitions of terms used in this study are included to ensure that there is agreement in meanings between this investigator and the reader. 
"Hearing Loss" Defined

"Hearing loss" refers to any degree of hearing impairment. It can be measured on a continuum ranging from "slight" to "profound," with profound indicating the greatest degree of loss (Yantis, 1985). Each successive category (slight, mild, moderate, severe, profound) involves progressively poorer hearing with inherent increased difficulty with verbal communication.

"Deaf," "Deafness," and "Hearing-Impaired" Defined

These terms are generally analogous and imply a hearing loss that is so severe as to cause the person to either not hear the sounds of his/her environment, or to hear sounds so poorly that they are essentially meaningless (Nowe11, 1985). An important distinction must be made between "pre-lingually" deaf and "post-lingually" deaf (Tannahill and Smoski, 1985). Post-lingually deafened persons include those who have lost their hearing at some time after the onset of language acquisition. Pre-lingually deafened individuals include those who were either born deaf or lost their hearing prior to the acquisition of language. The pre-lingually deaf make up the majority of hearing-impaired individuals in this country; hence, the present investigation focused upon this population of children. Another group that is affected by hearing loss, al though to varying lesser degrees, is the "hard-of-hearing."

"Hard-of-Hearing" Defined

This group includes any person who has a hearing loss but can still maintain functional auditory communication (Nowe11, 1985; 
Silverman \& Lane, 1970). It would generally include those who have lost some hearing gradually, usually as a result of chronic ear infections, noise exposure, or age factors. Their hearing loss will range from "mild" to "moderate-severe."

Current Methods of Hearing-Impaired Education

Manual. Manualism is a tradition of education for hearing-impaired children that was established in this country in the early 19th century (Silverman \& Lane, 1970). It utilizes sign language which is based on "natural gesture and pantomime with many obvious relationships between the signs and meaning" (Knauf, 1972, p. 751). Sign language began to be replaced by "oralism" towards the last half of the 19th century, and today is only found in residential schools for the deaf and among deaf adults (Knauf, 1972).

Oral. The "oral" technique uses visual, kinesthetic, and auditory cues to teach speech to hearing-impaired children without the use of sign language (Silverman \& Lane, 1970).

There is universal agreement among educators of the deaf that every deaf child should be given the opportunity to communicate by speech... The fundamental assumption of the oralists... is that training in speech and in speechreading gives an easier adjustment to a world in which speech is the chief medium of communication." (pp. 390-391)

Total Communication. The majority of schools in this country

used the oral approach until around 1960, when most programs made the transition to "total communication" (Nowell, 1985).

The term "total communication" actually refers to a philosophy of using any and all communication techniques that are appropriate for a particular deaf child... In most programs, however, a total communication approach means the use of both speech and sign language simultaneously. (pp. 783-784) 
HEARING LOSS POPULATION DEMOGRAPHICS

According to Schow and Nerbonne (1980), there are about 50,000 deaf school-age children, and 2,000,000 deaf including all ages in this country. If the hard-of-hearing are included, the total population of persons with a hearing deficit is between 14 and 16 million. In each case communication is affected to some degree, from slight interference with normal communication processes, to a total inability to communicate on the verbal level.

THE QUESTION OF HOW TO BEST EDUCATE THE HEARING-IMPAIRED STUDENT

The "most appropriate" educational method to use for deaf children has been a subject of considerable controversy between teachers of the deaf, deaf education administrators, parents of hearing-impaired children, and other persons involved in making educational placement decisions for these children (Knauf, 1972; Krantz, 1985; Ling, 1976; Myklebust, 1964; Nowe11, 1985; Silverman \& Lane, 1970). It is beyond the scope of this investigation to thoroughly examine supporting evidence for each of the conflicting philosophies, nor would such an effort resolutely answer the essential question: "Does the use of sign language adversely affect 1) the acquisition of speech and 2) the mental processes normally associated with spoken language?" (Ling, 1976) A cursory examination of some pertinent comments regarding the question is, however, in order. 
Manual

Rationale for the manual philosophy include the premises that: 1) sign language is the "natural" method of communication for deaf persons (Knauf, 1972; Menyuk, 1971); 2) some deaf children will not learn speech in any oral program (Klopping, 1972; Silverman and Lane, 1970); 3) time spent teaching speech skills to some deaf children may be better spent increasing "mental" development (Silverman \& Lane, 1970); and 4) some deaf children may ultimately prefer to limit communication to peers who use sign language (Knauf, 1972).

Sign language differs from spoken language in many ways. According to Bornstein (1979), when using sign language the sensory organ for information reception becomes the eye, and the mechanisms used for transmission are the hands, fingers, arms, face, and body. Bornstein stated that the use of vision for language reception results in two problems. First, language is transferred on a time basis, and the normal eye cannot process information temporally as effectively as the normal ear. Second, the eye can focus only on that part of space that is within the direct field of vision. It requires effort and attention to all parts of space with the eye, while the ear can receive information from all directions simultaneously. Bornstein explained that these alternate mechanisms for language transmission are subject to considerable limitations of reduced speed of transmission through the use of body movements and gestures, relative to the speech mechanism. 
Oral

The oral approach bases its philosophy on the premise that manual communication interferes with speech training (Ling, 1976). This view is disputed by Mindel and Vernon (1971), among others, who claimed that oral communication alone is not enough to develop full language capabilities in deaf children. Ling (1976) stated "the evidence as to whether teaching by sign detracts from speech development is at best equivocal" (p. 60). Ling pointed out that it is very unlikely that a deaf child can attend to sign language and speech simultaneously due to the totally different natures of their expression. The totally deaf child must rely solely on the visual input of signs and lip and mouth movements, which requires a high degree of skill in decoding both modes. It is unlikely that these children are capable of doing this, and it becomes a simpler task to interpret signs alone since they offer more direct cues of meaning than speechreading. The child with some residual hearing "hears" the auditory signal while speechreading and receiving the sign language of the sender. The information may become conflicting between synchronous signs and speech while all modes are competing for attention and memory storage.

Northcott (1973) reported that few hearing-impaired children who utilize sign language learn good speech production, while many orally trained children become good talkers, with the potential for early mainstreaming into normal educational environments. Montgomery (1966) has stated that many orally trained children never learn to speak any better than their signing peers. A definitive answer to this question 
could be obtained only by looking at two comparable groups of hearing-impaired children (one Total Communication and one Oral) who each receive maximal auditory and speech training with consistent use of hearing aids (Ling, 1976).

\section{Total Communication}

Nowell (1985) stated that total communication has gained recent acceptance as the prevailing philosophy of deaf education due to: 1) the many previous oral failures; 2) the increasing numbers of multiple-handicap children who have less of a chance for oral success; 3) professional support of the "use of sign language as a positive contribution to the social development of the deaf community" ( $p$. 784); and 4) the passage of the Education of All Handicapped Children Act (PL 94-142) which encourages placing hearing-impaired children in the "least restrictive environment."

Summary

It has been shown by Klopping (1972) that regardless of the educational method utilized for hearing-impaired children, a large proportion of them will never acquire any effective communication skills. This points out the need to take individual differences into account and tailor a program around the child's specific needs. The accomplishment of this end would require all involved persons to abandon preconceived philosophies and select the program that is truly most beneficial to the child.

No doubt fewer would fail if the most appropriate method for a particular child could be determined through early and ongoing evaluation and if teaching programs were substantially improved. (Ling, 1976, p. 6) 
It is clear that the speech intelligibility of deaf children is rated very low in most studies (see "Listener Judgments of the Speech Intelligibility of Deaf Children," p. 16 of this document), and that there has been virtually no improvement in speech production by these children in 40 years (Ling, 1976). Advocates for manual or total communication use this information to support their contention that it is necessary to use sign language to achieve communicative efficacy (at least with the "signing community"). This point could be well taken if oral programs were using every possible means to teach effectively, but the fact is, each program uses its own methodology, and while some are producing failures, others are producing successful individuals capable of communicating with the hearing world (Ling, 1976).

COMPARISON OF "AIDED" AND "UNAIDED" DEAF SPEECH

Existing literature comparing the speech of deaf children with hearing aids against their speech without hearing aids is practically nonexistent. According to Markides (1970, p. 133) "The speech intelligibility of hearing impaired children increased significantly with better use of...hearing aids." This was an observation unsupported by empirical data that typifies a prevailing attitude.

According to Stone (1987), the speech of profoundly hearing-impaired children seems to deteriorate very quickly when hearing aids are misfunctioning or removed. He pointed out that this is a widespread impression among teachers and parents of the hearing-impaired, al though research had not been conducted to confirm 
its validity. At the Tucker-Maxon Oral School, where Stone is director, much time and effort go into making sure that the students' hearing aids are functioning optimally at all times. It is felt that optimal hearing aid performance is critical to insure that their speech intelligibility is maintained at maximum levels of clarity.

\section{AUDITORY FEEDBACK}

Auditory feedback, the reception of one's own speech through both air and bone conduction, has received considerable study in regard to the speech intelligibility of normal and hearing-impaired persons.

Ludvigsen (1980) has suggested that the hearing-impaired child listening to his/her own voice without hearing aids is at a disadvantage. He stated that the situation is unfavorable because, relative to air conducted speech, the child's own voice is relatively weak due to the distance from mouth to ear, and because of attenuation of high frequencies due to the diffraction effect of the head. He said that the situation is unfavorable via bone conduction because only the lowest frequencies are transmitted through that route. The net result for a child with at least a moderate hearing loss is that he/she either will not hear his/her own voice, or will only perceive some low frequency components of his/her speech. Ludvigsen suggested that through use of hearing aids, the child will hear his/her own voice through the aids.

Van Riper and Irwin (1958) stated that auditory feedback is particularly important to developing children in order to acquire 
normal speech. According to Ling (1976):

However, there is no experimental evidence in regard to how much auditory self-monitoring the normally hearing child does, whether it is continuous or an intermittent function, or whether some aspects of speech require more attention to auditory feedback than others. (p. 78)

Siegel and Pick (1974) studied the speech of normally hearing adult subjects when auditory feedback was masked by high-level noise. No changes were noted, agreeing with the observations of numerous children and adults with established speech patterns who suddenly lose all hearing with no loss of intelligibility for months, or even years (Ling, 1976).

DiCarlo (1960) studied the effects of delayed speech feedback on the speech of hearing-impaired children. Results indicated that the speech of hearing-impaired children trained auditorally was more affected by the delayed speech feedback than was the speech of children who were educated without hearing aids.

Goff (1974) used amplified auditory feedback in a study attempting to encourage the vocalizations of hearing-impaired children. The results of this pilot study suggested that auditory feedback during vocalization may have facilitating effects when amplified and played back to young deaf children.

\section{ATTRIBUTES OF HEARING-IMPAIRED SPEECH}

Overall Attributes of Hearing-Impaired Speech

Black (1971) observed that the deviant speech productions of hearing-impaired persons are multiple and seem to affect every aspect of normal speech production. He generalized that "the speech of deaf 
children differs from normal speech in all regards" (p. 156). A review of articles dealing with speech patterns of the hearingimpaired makes this point obvious.

The classic study by Hudgins \& Numbers (1942) determined phoneme errors to result mainly from neutralization (tendency for the tongue to assume a central position) or diphthongization of vowels, deletion of initial and final consonants, inability to produce consonant clusters, voicing and nasality errors, and substitutions.

Angelocci (1962) and Angelocci, Kopp, and Holbrook (1964) found three striking differences between deaf and normal speech. First, in deaf speech fundamental frequency is higher. This is thought to be due to increased vocal fold tension for the purpose of increased awareness of voicing (Pickett, 1968). Second, there is greater variation in formant frequency positions, resulting from inaccurate vowel production. Third, the relationships of the first two formants to each other are more distorted, again due to inaccurate vowel productions.

Specific Attributes of Hearing-Impaired Speech

Attributes of speech which contribute to decreased intelligibility of deaf speakers are varied and largely addressed by research on an individual basis.

Vowel Errors. Of all the speech articulators involved in vowel production, the tongue and the lips are most responsible for creating the articulatory positions necessary for target vowel production (Ling, 1976). Production of most consonants is accomplished by the articulators making contact with each other, allowing the development 
of a tactile sense which aids in articulatory placement. Wansink and Povel (1986) pointed out that vowels are particularly difficult for hearing-impaired children to produce because, unlike most consonants, the articulators barely make contact during vowel production, causing reduced monitoring of speech through the tactile sense.

In order to develop a sense of tongue and lips placement for target vowel production, a great deal of training is necessary to establish reference points for the articulators (Wansink \& Povel, 1986). Without such reference points all vowels tend to be neutralized by hearing-impaired persons. This neutralization has been demonstrated spectrographically by Monsen (1978), showing a decreased distance between the first and second formants.

Other frequent vowel error patterns which were found by Hudgins and Numbers (1942) and later by Angelocci, Kopp, and Holbrook (1964) include substitution, diphthongization, and nasalization.

Consonant Errors. Consonants require greater constriction of the vocal tract than vowels (Ling, 1976). The articulatory positions and movements are more varied than vowels and often require greater speed and more precise placement of the articulators. The range of intensity is much greater for consonants than for vowels. There is also greater variation of durational and frequency characteristics of consonants than vowels, according to Ling (1976), resulting in some consonants being more difficult to produce than vowels, and some more difficult to hear by the hearing-impaired person. The greater tactile cues of consonants, however, tend to establish an inherently stronger sense of position than vowels, resulting in easier production accuracy 
when auditory feedback is reduced.

Since speech errors are found in all aspects of hearing-impaired speakers' productions, it follows that, with all the variation in consonant production, there will be found a multitude of consonant errors. This is, in fact, the case, but studies seem to indicate some errors predominating. Hudgins and Numbers (1942) found that in children with the most severe hearing impaiments, errors related to voicing, initial consonants, and nasality were most common.

Markides (1970) found similar results with specific categories of errors including the following: 1) Deaf children most frequently omitted the plosives $/ g /, / d /$, and $/ k / ; 2$ ) Unvoiced plosive consonants were typically substituted for voiced cognates; 3) Final /p/ was the most frequently distorted plosive consonant, accompanied by excessive breathiness; 4) Nasals were often omitted, with / $/$ / being the most frequent omission; 5) Substitutions of nasals were most frequently changes in manner of articulation; 6) The most commonly distorted nasal consonant was $/ \mathrm{m} / ; 7$ ) The plosives $/ t /$ and $/ p /$ were the most frequently substituted phonemes for fricatives; 8) The most frequently distorted fricatives were $/ \mathrm{s} /, 1 \Theta /$, and $/(/$; and 9$)$ The most frequentiy distorted, substituted, and omitted phoneme was the affricative $/ t / 1$.

These findings represent trends in consonant errors by hearing-impaired persons and are by no means complete. It does point out, however, the extent of defective consonant production in this population and the difficulty in categorizing the errors. 
Errors of Prosody. Errors of prosody in the speech of the hearing-impaired include errors of duration, intensity, and pitch. These are the more subtle characteristics of speech that, in themselves, carry much of the information being conveyed orally. Monsen (1978) noted that word and sentence duration of deaf speakers is typically excessively long. He also stated "the pitch contour over individual words is either too high, too monotonal, or simply 'inappropriate'" (p. 208). John and Howarth (1965) found the duration of monosyllabic words was approximately twice that of normal hearing children, agreeing with Monsen's findings. They concluded that durational factors are critical to the intelligibility levels of deaf speech. Hudgins and Numbers (1942) also suggested that abnormal rhythmic or prosodic pattern is one of the major factors contributing to unintelligibility.

The problem of teaching the suprasegmental aspects of speech to hearing-impaired children is enormous. Deaf educators must constantly face the question of prioritizing the time spent on articulatory versus nonarticulatory components of speech. Maassen and Povel (1985, p. 877) stated "in order for these speakers to become more intelligible, improving their articulation is more important than improving their production of temporal structure and intonation."

\section{LISTENER JUDGMENTS OF THE SPEECH INTELLIGIBILITY OF DEAF CHILDREN}

The production of speech varies according to numerous parameters and in multiple dimensions. For a listener to understand speech, all of these factors must be integrated, delegating each part of the 
acoustical speech message to a gestalt pattern that is interpreted according to the language code (Monsen, 1983). While each of these acoustical parameters (e.g., fundamental and harmonic frequencies, formant frequencies, duration) may be measured directly, their relative contributions to speech intelligibility cannot be determined by acoustical analysis.

Another method of measuring the speech intelligibility of deaf children is to present their speech to listeners who then make judgments regarding intelligibility. While this method may provide a subjective intelligibility index for any given child, it cannot identify the acoustical or articulatory processes causing the differences (Monsen, 1978).

In many or most cases it is difficult for even a highly trained observer to extract the source of a speech error-that is, the "real acoustic reason" and its articulatory counterpart-for his not understanding a particular word. The listener experiences this difficulty in extracting the sources of errors in the speech of the hearing-impaired because speech is a complicated, coarticulated code rather than a simple linear string of symbols. Speech errors cannot be detected like typographical errors on a page. (p. 198)

\section{Experienced Versus Inexperienced Listening Judges}

As a means of assessing intelligibility in deaf children, judges familiar with deaf speech (experienced) and judges unfamiliar with deaf speech (inexperienced) have been used (Monsen, 1983). The listener's previous experience in hearing the speech of the deaf has been an issue concerning different ratings between the two groups. Mean intelligibility, to inexperienced listeners, of recorded speech of the deaf has been markedly similar in some studies. Smith (1975) reported mean intelligibility of 18.7\%. Brannon (1964) 
reported 20.7\%, while John and Howarth (1965) and Markides (1970) reported $19 \%$ and $19.1 \%$, respectively. In each of these studies age groups, hearing loss, and scoring procedures were all comparable. Monsen (1983) looked at different factors ostensibly affecting perception of speech intelligibility and found "previous exposure to deaf speech" to be one of the most influential. He reported this difference to be greater when listeners heard less intelligible speech than when they listened to more intelligible speech. He also found this effect to vary according to the complexity of the speech sample. His results ranged from $2 \%$ greater intelligibility for experienced listeners listening to simple sentences, to $30 \%$ greater intelligibility for experienced listeners listening to complex sentences. He also pointed out that "listener experience" varies on a continuum from one extreme of "no exposure to deaf speech" to the other extreme of "full-time teachers of the deaf." Everyone else falls somewhere in between, relative to degree of previous experience. When comparing the scores of these two extremes, while ignoring all other variables, he found a difference of $20 \%$.

Thomas (1964) reported that experienced listeners understood an average of $24 \%$ more than the inexperienced 1 isteners in his study. He also reported an improvement of $16 \%$ if the listener was allowed to visualize the speech production. Markides (1970) found that his experienced 1 isteners understood about $12 \%$ more than his inexperienced listeners, when listening to the speech of severely and profoundly deaf speakers. Monsen (1978) found this advantage to be $9 \%$. In another study, Thomas (1964) reported experienced listeners rated 
intelligibility one-third again as high as judgments of the same speech samples by inexperienced listeners.

Effect of Experience on Inexperienced Listeners.

In Monsen's (1978) study, two groups of listeners were used to make intelligibility judgments of the same speech samples of hearing-impaired children on audio tape. One group had had extensive contact with the speech of the hearing-impaired, and they averaged approximately $9 \%$ better understanding of deaf speech than the inexperienced listeners. What is significant about these findings, however, is the rapid effect of accumulated experience on the inexperienced listeners. At the onset of the listening task, the experienced listeners understood $14 \%$ more than the inexperienced listeners. After listening to three tapes this difference decreased to only $5 \%$ greater understanding by the experienced listeners.

The data...indicate that while experience in hearing the hearing-impaired speak is a considerable advantage in understanding what is said, it is an advantage that is rather quickly and easily acquired. (Monsen, 1978, p. 213)

SPEAKER AND CONDITIONAL VARIABLES AFFECTING INTELLIGIBILITY RATINGS

Monsen (1983) studied the different effects of variables upon the intelligibility ratings of severely to profoundly hearing-impaired adolescents. Variables included: the phonologic, syllabic, and syntactic structure of the speech sample; the ability to see the speaker; contribution of semantic context; repetition of utterances; and listener experience in hearing the speech of the hearingimpaired. Significant differences were found with respect to: 
1) complexity of sentences; 2) experienced versus inexperienced listeners; 3) sentences "in context" versus "out of context;" and 4) addition of visual cues to the speech sample. The average intelligibility scores for all listeners and all talkers combined, regardless of variables, was $79 \%$. This ranged from $57 \%$ to $96 \%$, depending on the combinations of the different variables.

When the intelligibility of the speech of hearing-impaired children is measured, the usual procedure is to record words or sentences and present these speech samples to a panel of listeners. Although this procedure provides much useful information, it is different from the real-life situations in which hearing-impaired individuals actually communicate. (Monsen, 1983, p. 288)

Jensema, Karchmer, and Trybus (1978) assessed intelligibility through a rating system. Smith's (1973) study is an example of judges listening to the speech of hearing-impaired subjects directly, while the responses of the judges to these subjects were evaluated in different ways to assess their understanding of the subjects' speech. Intelligibility of deaf children has been studied over time, e.g., Hudgins (1960) determined 35\% intelligibility at the beginning of a five-year period, and 40\% at the end. John and Howarth (1965) looked at average intelligibility before and after a special training session aimed at improving the time factors of speech, determining $29 \%$ before and $45 \%$ after. Depending upon the conditions and procedures used in any particular study, intelligibility ratings have varied accordingly.

Correlation Between Intelligibility and Hearing Loss

While the exact mechanisms involved in the dysfunction of speech processes for hearing-impaired speakers are complex, a direct negative correlation between intelligibility of these speakers and their 
hearing loss has been well-documented (Monsen, 1983).

Studies by Jensema et al. (1978), Kyle (1977), Smith (1973), Monsen (1978), and Markides (1970) have all documented that the pure-tone average (average of hearing thresholds at 500, 1000, and $2000 \mathrm{~Hz}$.$) reliably indicates 30-40 \%$ of the differences in speech intelligibility. As Monsen (1978) has pointed out, however, this indicator becomes less reliable as the level of hearing loss increases. In other words, an audiogram that indicates good hearing is a good indicator of speech intelligibility, while an audiogram reflecting poor hearing thresholds cannot reliably predict speech intelligibility, which can range from poor to good at high levels of hearing loss.

In Monsen's (1978) study, the average intelligibility of the hearing-impaired talkers was $76 \%$. Breaking this percentage down according to degree of hearing loss, the intelligibility of the severely hearing-impaired group was $91 \%$, while that of the profoundly hearing-impaired group was $67 \%$. These scores were higher than many studies investigating intelligibility of deaf speech for a number of reasons, primarily because the sentences that the subjects were required to speak were considerably simpler than the previously cited studies.

Speech Intelligibility as a Function of Age

Jensema et al. (1978) looked at listener ratings of speech intelligibility as a function of age for 976 hearing-impaired subjects ranging in age from 4-23 years. They reported that intelligibility did not increase with age. If this finding can be generalized to the 
hearing-impaired population, it would mean that, for example, a typical 15 year-old would not be more intelligible, on the average, than an 8 year-old.

Complexity of Utterance

The types of materials used in the production of speech samples by hearing-impaired children may vary from extremely simple to extremely complex. The resulting "measure of intelligibility" will vary according to the complexity of the chosen materials (Monsen, 1983). For example, the use of extremely complex materials will render practically any hearing-impaired child unintelligible, while the use of simpler materials will increase intelligibility accordingly. Linguistic Complexity. A speaker has control over the linguistic complexity of words only inasmuch as the language will allow alternate choices for those words (Monsen, 1983). Some words allow simplification by altering the word or substituting a simpler word, while other words must be used without alteration or substitution due to the lack of alternate semantic choices. Monsen found an effect of decreased intelligibility when more linguistically complex words were included. He suggested that this was because linguistic complexity for any individual word increases the articulatory demands upon the speaker, resulting in reduced intelligibility.

Syntactic Complexity. Monsen (1983) found a correlation between syntactic complexity and intelligibility judgments. His listeners rated sentences with increased syntactic complexity to be less intelligible than syntactically simpler sentences. Monsen suggested 
that reasons for this difference might include the increased need by listeners for prosodic features to interpret increasingly complex sentences. Since hearing-impaired speech typically includes less prosodic information than "normal" talkers' speech, this lack of information may cause the decreased intelligibility judgments. Monsen also pointed out that there may be an inherent factor of increased difficulty of production and comprehension in increasingly complex sentences.

Syntactic complexity is largely under the control of the talker (Monsen, 1983). Thus a hearing-impaired individual can cause his/her speech to become more intelligible to a listener merely by simplifying sentences. Monsen suggested that this factor of increased intelligibility as a function of sentence simplification may be pertinent in explaining the results of Jensema et al. (1978) where they found that intelligibility did not increase as a function of age. This could be explained by the fact that intelligibility of younger children may be judged on the basis of simple words and sentences while that of older children may be judged on the basis of more complex words and sentences.

Context of Utterance

Another important factor, which has no relation to the articulatory proficiency of the speaker, is the context of the communicative utterance (Monsen, 1983). Some contexts provide useful information to the spoken message, while others provide none. Monsen found that the addition of contextual information increased intelligibility an average of $14 \%$ across all talkers, listeners, and 
conditions. He advised discretion in interpreting these results since the difference occurred under laboratory conditions of artificially adding contextual information to otherwise neutral sentences.

The verbal contexts of everyday conversations are often semantically more complete, involving an entire repertoire of characters and events known by both the talker and the listener. Conversation typically involves producing utterances that bear a close relation to what has previously been said by either or both participants. (p. 293)

\section{Repetition of Utterance}

A common strategy for hearing-impaired speakers, to clarify what a listener may not have understood, is to repeat the utterance. Monsen (1983) found that an exact replay of a tape-recorded sentence, allowing the listener a second chance to hear the sentence, increased overall intelligibility scores by $7 \%$. He pointed out, however, that an exact replay of a sentence does not include corrections that a hearing-impaired speaker would make due to: 1) intuitive knowledge of mistakes he/she may have made; or 2) understanding what portion of the message was misunderstood by the listener. These real-life modifications would have a corresponding increase on intelligibility ratings when looking at the repetition effect.

Visibility of the Speaker

Monsen (1983) found that the ability to visualize the speaker's face improved overall intelligibility by $14 \%$. Monsen explained that, with an already decreased articulatory output by hearing-impaired children, the addition of visual cues augmented the speech information. 
Interactions Between Different Factors Affecting Intelligibility

While there are numerous factors affecting speech

intelligibility, it is unknown how these factors overlap (Monsen, 1983). These factors are not mutually exclusive, but must combine in some manner to affect the degree of intelligibility. Monsen emphasized that in order for an intelligibility rating to be relevant, all of the different identifiable variables must be specified.

\section{CORRELATION OF SPEECH ERRORS AND INTELLIGIBILITY JUDGMENTS}

Monsen (1978) found three significant consonant errors in deaf speech most related to intelligibility. First, he noted a positive correlation between distances between voice-onset-times of homorganic (differing in voicing/unvoicing only) consonants and speech intelligibility. Second, he found no visible boundary, through spectrographic analysis, between nasals or liquids and their following vowels. Finally, he found greatly elongated initial nasals and liquids.

These three variables accounted for approximately three-quarters of the variance in these scores. First, the voice-onset-time (VOT) difference between $/ t /$ and $/ d /$ accounted for $48.5 \%$ of the variance. This was found to be a systematically deviant pattern in deaf speech caused by the inability to make the phonemic distinction between voiced and voiceless stop consonants. Second, the second formant difference between $/ i /$ and $/ J /$ accounted for $20.3 \%$ of the variance. This is a consequence of neutralization of vowels. Third, the liquids and nasals accounted for $4 \%$ of the variance. In hearing-impaired 
speech there is typically no clearly defined boundary between initial liquids and nasals and the following vowels, in addition to a greatly increased duration of these speech sounds. 
CHAPTER II I

METHOD

The essential question this study attempted to answer was whether naive listeners would perceive a difference in intelligibility between the amplified and unamplified conditions in the speech of hearing-impaired children. The research hypothesis stated that if these children were in the unaided condition for a significant period of time, the reduced self-monitoring ability imposed by the removal of amplification would result in a reduction of intelligibility as perceived by listeners. The null hypothesis negated this relationship and stated that there was no difference in perceived intelligibility between the two conditions. The alternative hypothesis stated that there is a difference. To control the probability of making a Type I error, i.e., rejecting a true null hypothesis, an alpha level of .01 was designated.

\section{SUBJECTS}

The subjects were ten children with a sensori-neural hearing loss of $90 \mathrm{~dB} H \mathrm{H}$ or more, based on the pure-tone average (PTA), or the average hearing loss, at the frequencies 500, 1,000, and 2,000 Hz. The age range was 8-13 years with a mean age of 10.7 years (Table I). They were chosen from the Tucker-Maxon Oral School in Portland, Oregon, which utilizes the oral/aural approach with dependence on amplification for auditory learning. Nine of the children were 
pre-lingually deaf and had been fitted with hearing aids by age 3 . Eight of the children had attended parent-infant programs which stressed auditory training with emphasis on optimizing residual hearing by amplification. The exceptions were: 1) One child was diagnosed as profoundly hearing-impaired between 3 and 4 years of age (possibly post-lingual), fitted with amplification by age 4 , and did not attend a parent-infant program; and 2) One child did not attend a parent-infant program, and had been fitted with a cochlear implant 1 year prior to the speech samples.

TABLE I

CHILD SUBJECT INFORMATION

Subject \# Sex Age Exceptions

\begin{tabular}{rrrl}
\hline 1 & $F$ & 11.7 & None \\
2 & $F$ & 13.4 & None \\
3 & $M$ & 12.7 & $\begin{array}{l}\text { Cochlear implant for } 1 \text { year; no } \\
\text { parent-infant program }\end{array}$ \\
4 & $F$ & 8.7 & None \\
5 & $F$ & 8.8 & None \\
6 & $F$ & 8.8 & None \\
7 & $F$ & 8.2 & None \\
8 & $M$ & 8.9 & $\begin{array}{l}\text { Diagnosed between } 3-4 \text { years; aided by } 4 \\
\text { years; no parent-infant program }\end{array}$ \\
9 & F & 10.3 & None \\
10 & M & 9.8 & None
\end{tabular}


PROCEDURE

Materials

Sentences from the CID Everyday Sentences, which were developed to represent everyday American speech, were used as the speech sample (Appendix A). List B was chosen from the CID Everyday Sentences due to its inclusion of appropriate vocabulary for the speakers. An al ternate list of 10 sentences was prepared in the event any of the vocabulary was unfamiliar to the speakers (Appendix B). These alternate sentences were individually selected from other sentence lists from the CID Everyday Sentences according to their simplicity of vocabulary.

The speech samples were recorded in the audiometric testing booth at the children's school. The sound booth was measured for ambient noise while school was in session with a reading of $29 \mathrm{~dB} H \mathrm{HL}$ on the A scale. A Philmore DC93 microphone (Appendix C) was maintained approximately 10 inches from each speaker's mouth, and the speech sample was recorded on a Dual C 939 tape recorder (Appendix C).

Each subject produced the ten-sentence sample two different times, according to the two conditions being compared, yielding 200 sentences in a total of 20 samples. The first sample was obtained at the beginning of a school day, at school, with the subject's hearing aids on and functioning normally. The second, identical sample was recorded the following morning with the subjects' hearing aids off. Under the second condition each subject was required to have gone without his/her hearing aids for 18 hours $\pm 1 / 2$ hour and including sleep time) to provide a reasonably maximal period of time in the 
unaided condition. This was accomplished by requiring each subject to leave his/her aids with his/her teacher at the end of the school day preceding the morning that the "unaided" sample was to be obtained. For the purposes of this study the child with the cochlear implant turned off this device during the period that the other children's hearing aids were removed and left at school.

For each speech sample a speaker was brought into the sound booth and seated in front of the microphone. This investigator was seated facing the child. Each subject was asked to first read the ten sentences silently to confirm familiarity with all of the included vocabulary, and to report any problems with the words contained in the sentences. When the child indicated readiness to perform the task, this investigator switched on the recording deck and cued the child to read each sentence out loud. After the ten sentences had been recorded, the child's task was completed and a new subject was brought into the booth.

\section{Intelligibility Judgments}

When all of the speech samples had been collected, a listening tape was prepared on a Teac 7030SL tape deck (Appendix C) which consisted of pairing together identical sentences from each subject in the aided and unaided conditions. Ten subjects participated in the study, and 10 sentences were included for each sample, resulting in 100 sentences to be compared, or a total of 200 sentences when each condition was paired with the contrasting condition.

The tape began with verbal instructions from this investigator to the listening judges (Appendix D). Following the instructions were 
the 100 sentence pairs plus 10 sentence pairs which served as a reliability test.

The order of subjects on the listening tape was selected by drawing their names randomly. When one subject's name had been drawn, however, his/her sentences were dubbed onto a master listening tape in the order originally obtained in the speech sample (Appendix A). To determine the order of "Aided" and "Unaided" for each sentence pair, a lottery procedure was employed. For example, if the lottery resulted in "Aided" being the first sentence presented in a given sentence pair, then the second sentence in that pair was "Unaided." Conversely, if "Unaided" was the sentence presented first, then "Aided" was presented second, and so on.

After the first subject's ten sentence pairs had been dubbed onto the master listening tape, the second subject's name was drawn at random and that subject's ten sentence pairs were dubbed onto the tape in the order of the CID sentence list. The dubbing continued in this manner until all ten subjects had been represented on the master tape. When all of the sentence pairs had been recorded, a listening-judges-reliability-test was added by selecting ten sentence pairs that represented a random $10 \%$ sample of the original 100 sentences. This was accomplished by choosing each subject randomly, and presenting one sentence pair from that subject. For example, the first subject was chosen at random, and that subject's "sentence number one" was presented on the tape. Then the second subject was selected randomly, and that subject's "sentence number two" was presented. The order of presentation for the reliability check 
sentence pairs occurred in this manner until all ten subjects had been represented.

Once the master listening tape had been prepared, 63 listening judges were selected according to the criteria of: 1) lack of experience hearing "deaf speech;" 2) no reported hearing loss; and 3) enrolled as an undergraduate or graduate student at PSU. The judges came in groups to a Listening Lab at Portland State University, to perform the listening task. The Lab was equipped to play back a master tape to each of 30 listening booths containing headphones for up to 30 listeners. The judges listened to the 30 minute tape and marked their judgments on a scoresheet provided by this examiner (Appendix E). For each sentence pair three choices were allowed: 1) "Sentence \#1 Most Intelligible;" 2) "Sentence \#2 Most Intelligible;" and 3) "No Difference in Intelligibility." After listening to each sentence pair, each judge made one of the three choices.

Judges 1 istened to the master tape through earphones rather than in a sound field condition in order to reduce the inherent variability in the sound field condition. In a sound field, each judge would be in a different position relative to the loudspeakers and at different distances from the speakers. It was important to provide identical conditions for the naive listeners in order to ensure that each listening judge was receiving the same signal, and listening through earphones was the optimum means of achieving that end. Additionally, earphones provided the maximum clarity and signal-to-noise ratio, allowing the greatest ability to distinguish between sentences that 
may have been subtle in their intelligibility differences.

\section{Total Listener Decisions: Original Sentences}

When all 63 listening judges had completed the listening task, their scoresheets were summed to provide the raw totals for all of their decisions. Each sentence pair produced by the children ("Aided" and "Unaided") allowed three possible choices resulting in a raw number in each of the three boxes: 1) "Sentence \#1 Most Intelligible;" 2) "Sentence \#2 Most Intelligible;" and 3) "No Difference" (Appendix E). Since 63 judges performed the listening task, there were 63 decisions per sentence pair, distributed between the three boxes; hence, each child produced 10 sentence pairs yielding 630 listener decisions per child. A total of 10 children produced the 10 sentence pairs each, thus the grand total possible for all of the judges should have been 6,300 judgments (if one decision was made by each judge for each sentence pair). The grand total was actually 6,296, due to the lack of response to one sentence pair each by four judges.

\section{STATISTICAL ANALYSIS OF DATA}

In determining which kind of statistical test to perform on these data, it was first necessary to choose between significance tests and correlation coefficients. According to Linton and Gallo, (1975, pp. 19-20) "Any study that implicitly or explicitly involves the comparison of two or more groups or conditions requires a significance test." Since this study was to determine if differences existed between two conditions, a statistical test of significance was required to answer the question. 
Chi Square was the significance test of choice for this study. While other significance tests may have been applied, Chi Square has the advantage of simplicity with enough flexibility to be adaptable to a variety of designs (Linton \& Gallo, 1975).

The following statistical analysis was used: one-way Chi Square; one independent variable with three levels. See Appendix F for the complete rationale for use of Chi Square in this study.

An individual distribution resulted for each of the 100 sentence pairs, leaving a potential to statistically analyze the judges' total decisions for: 1) each sentence pair; 2) each individual subject's 10 pairs of sentences; and/or 3) the combined totals for all sentence pairs by all subjects. These combined totals provided information on the listeners' overall perceptions of the children's productions and would be most suggestive of a trend, if one existed, for how the different conditions were perceived. In addition, the subjects could be looked at individually to determine if the judges perceived any differences for each subject separately. This information could be valuable for finding whether or not an individual's speech is perceived differently between the two conditions, but would not be representative of the population of children who use hearing aids. To further break the data down and look at specific pairs of sentences would only be representative of one sentence pair for one child, and would not be of any value other than determining if that single sentence was spoken differently between the two conditions by the individual involved. 
CHAPTER IV

\section{RESULTS AND DISCUSSION}

\section{RESULTS}

Totals: "On" Versus "Off"

Out of the total of 6,296 decisions for the original sentences, 2,167 choices (34\%) were for the "Hearing Aids On" condition most intelligible, 1,740 choices (28\%) for "Hearing Aids Off" most intelligible, and 2,389 choices (38\%) for "No Difference in Intelligibility" (Table II). Listener decisions per each individual speaker may be seen in Appendix G.

TABLE II

COMPARISON OF TOTAL CHOICES FOR "HEARING AIDS ON," "HEARING AIDS OFF," AND "NO DIFFERENCE IN INTELLIGIBILITY"

\begin{tabular}{lcccc}
\hline & $\begin{array}{c}\text { "Hearing Aids } \\
\text { On" Most } \\
\text { Intelligible }\end{array}$ & $\begin{array}{c}\text { "Hearing Aids } \\
\text { Off" Most } \\
\text { Intelligible }\end{array}$ & $\begin{array}{c}\text { "No Difference } \\
\text { in } \\
\text { Intelligibility" }\end{array}$ & Total \\
\hline $\begin{array}{l}\text { Number of } \\
\text { Choices }\end{array}$ & 2,167 & 1,740 & 2,389 & 6,296 \\
$\begin{array}{l}\text { Percentage } \\
\text { of Total }\end{array}$ & $34 \%$ & $28 \%$ & $38 \%$ & $100 \%$ \\
\hline
\end{tabular}


Thirty-eight percent $(2,389 / 6,296)$ of the total choices indicated no perceived difference in intelligibility between the aided and unaided conditions. This left sixty-two percent $(3,907 / 6,296)$ of the total choices reflecting a perceived difference in intelligibility between the two conditions (Table II). Considering the choices that were made for one or the other condition being more intelligible, 55\% of those choices designated the "Aids On" condition as being most intelligible (Table III). To determine whether this difference was statistically significant Chi Square analysis was performed.

TABLE II I

\section{COMPARISON OF LISTENER CHOICES REFLECTING A PERCEIVED DIFFERENCE BETWEEN THE TWO CONDITIONS: "HEARING AIDS ON" VERSUS "HEARING AIDS OFF"}

\begin{tabular}{lccc}
\hline & $\begin{array}{c}\text { "Hearing Aids } \\
\text { On" Most } \\
\text { Intelligible }\end{array}$ & $\begin{array}{c}\text { "Hearing Aids } \\
\text { Off" Most } \\
\text { Intelligible }\end{array}$ & $\begin{array}{c}\text { Total Choices } \\
\text { Reflecting a } \\
\text { Perceived } \\
\text { Difference }\end{array}$ \\
\hline \# Choices & 2,167 & 1,740 & 3,907 \\
$\%$ of Total & $55 \%$ & $45 \%$ & $100 \%$ \\
\hline & & \\
"On" Versus "Off" Comparison & &
\end{tabular}

Chi Square revealed that the "Aids On" condition was chosen as "Most Intelligible" significantly more often than the "Aids Off" condition, to the .01 level of confidence. Results for total decisions are found in Table IV, while analysis of each individual speaker is displayed in Appendix G. 
TABLE IV

RESULTS OF CHI SQUARE ANALYSES

FOR SPECIFIC COMPARISONS

Comparison

"Aids On"

"Aids Off"

Sentence \#1

versus

Sentence \#2
"Aids On"
column 1
versus
"Aids Off"
column 1

"Aids On"

column 2

versus

"Aids Off"

column 2

\section{$x^{2} \quad x^{2}$}

Unweighted weighted Indication

46.6673

$N / A$

Judges chose "Aids On" as

"Most Intelligible"

significantly more often

than "Aids Off"

$684.2142 \quad \mathrm{~N} / \mathrm{A}$

Judges chose sentence \#2 as

"Most Intelligible"

significantly more often

than sentence \#1

$26.6514 \quad 14.5723$

Judges chose "Aids On" in column 1 as "Most

Intelligible" significantly more often than "Aids Off" in column 1

$23.0996 \quad 7.3049$

Judges chose "Aids On" in column 2 as "Most

Intelligible" significantly more often than "Aids off" in column 2

Note: for significance to the .01 level of confidence, with 1 degree of freedom, $X^{2}$ must be greater than or equal to 6.63490

Sentence \#1 Versus Sentence \#2 Comparison

A comparison of the total choices for sentences 1 and 2, suggested that a "repetition of utterance" effect occurred (Table V), i.e., the judges appeared to choose the repeat sentence as "Most Intelligible," consistent with Monsen's (1983) findings. Twenty-nine percent of these choices were for sentence \#1 while $71 \%$ were for sentence \#2. It was noted in Table IV that Chi Square analysis determined the judges chose sentence \#2 decidedly more often than 
sentence \#1 at the .01 level of confidence. Analysis of judges' choices for sentence \#1 versus sentence \#2, per each individual speaker, may be observed in Appendix $H$.

\section{TABLE $V$}

COMPARISON OF TOTAL CHOICES: SENTENCE \#1

VERSUS SENTENCE \#2

Sentence \#1

Number of

Choices

Percentage

of Choices

1,136

$29 \%$
Sentence \#2

2,771

3,907

$71 \%$

Total

It should be noted that the order of each sentence pair ("Aids On" or "Aids Off" presented first) was randomized according to lottery, with the result that $52 \%$ of the sentences presented first were the "Hearing Aids On" condition, and $48 \%$ of those presented second were the "On" condition. While there were more "Aids On" sentences in the first column, the predominant number of choices were, however, for the second column. In spite of this "repetition of utterance" effect, the judges still chose the "Hearing Aids On" condition significantly more often than the "Off" condition (Table IV). While this may appear contradictory, the results were actually compiled through two means. The first consisted of counting the total choices for the "Aids On" condition and comparing that to the total for "Aids Off," regardless of which columns they came from. As previously stated, the statistically significant choice was for the 
"Hearing Aids On" sentences being most intelligible.

The second counting procedure looked strictly at the total choices for column 1 and compared that total to the total choices for column 2. This revealed the "repetition of utterance" effect with column 2 being chosen significantly more often. In order to interpret this seeming contradiction, it was necessary to make other comparisons by additional means.

"Aids On" in Column 1 Versus "Aids Off" in Column 1

In an effort to eliminate the "repetition of utterance" effect the two sampled conditions were compared within each individual column. Stated differently, the total choices for "Hearing Aids On" in the first column were compared to the total choices for "Hearing Aids Off" in the first column (Table VI). These choices reflected only the judges' choices for the first sentence in each pair; hence, the effect of predominantly choosing the second sentence was not a factor. Once again, it can be seen in Table IV that Chi Square revealed the judges chose "Hearing Aids On" significantly more often than "Hearing Aids Off," to the .01 level of confidence. 
TABLE VI

COMPARISON OF "HEARING AIDS ON" CHOICES IN COLUMN 1

VERSUS "HEARING AIDS OFF" CHOICES IN COLUMIN 1

\begin{tabular}{|c|c|c|c|}
\hline & $\begin{array}{l}\text { "Hearing Aids } \\
\text { On" Column } 1\end{array}$ & $\begin{array}{l}\text { "Hearing Aids } \\
\text { Off" Column } 1\end{array}$ & Total \\
\hline $\begin{array}{l}\text { Number of } \\
\text { Choices }\end{array}$ & 655 & 481 & 1,136 \\
\hline $\begin{array}{l}\text { Percentage } \\
\text { of Choices }\end{array}$ & $58 \%$ & $42 \%$ & $100 \%$ \\
\hline Unweighted $\mathrm{fe}_{\mathrm{e}}$ & 568 & 568 & 1,136 \\
\hline Weighted $f_{e}$ & 590.72 & 545.28 & 1,136 \\
\hline
\end{tabular}

Computation of Chi Square requires determination of an expected frequency $\left(f_{e}\right)$ for each comparison made. In order to compute Chi Square for the within-column analyses it was necessary to use two different expected frequencies for each individual comparison. The first (unweighted) $f_{e}$ was chosen based on a completely random selection of "Aids On" versus "Aids Off" (Table VI). This unweighted $f_{e}$ would result in an equal number of choices for "Aids On" as for "Aids Off." Using the unweighted expected frequencies, the overall choices for "Aids On" being most intelligible was significant to the .01 level of confidence (Table IV).

The second numbers used for the expected frequencies were the weighted numbers, according to the actual frequencies of sentences spoken in the "Aids On" and "Aids off" conditions (Table VI). Since $52 \%$ of the sentences presented first in column 1 were with "Hearing Aids On," and $48 \%$ of those sentences were with "Hearing Aids Off," the 
expected frequencies were adjusted to reflect this unequal distribution. This allowed for a weighted randomization of choices according to the actual distribution of conditions. Stated differently, there was not a 50-50 distribution of sentences in each condition in the first column and, by weighting according to the actual distribution, this compensated for the imbalance by more realistically randomizing the expected frequencies. Chi Square analysis of "On" versus "Off" conditions in column 1, using weighted expected frequencies, remained significant for the judges choosing "On" more often than "Off" (Table IV).

Within-column analysis was also performed on the totals in column 2, which reflected the totals of choices for the second sentence only out of each sentence pair (Table VII). The "Hearing Aids On" choices for column 2 were compared to the "Hearing Aids Off" choices for column 2 in another effort to eliminate the "repetition of utterance" effect. The judges chose "Hearing Aids On" significantly more often than "Hearing Aids Off" to the .01 level of confidence (Table IV). When the expected frequencies were weighted according to the actual distribution of "On" and "Off" conditions (Table VII), as was done for column 1, Chi Square indicated that the judges still chose "On" significantly more often than "Off," to the .01 level of confidence (Table IV). 
TABLE VII

COMPARISON OF "HEARING AIDS ON" IN COLUMN 2

TO "HEARING AIDS OFF" IN COLUMN 2

"Hearing Aids

On" Column 2
"Hearing Aids

off" Column 2
Total

2,771

Number of

Choices

1,512

1,259

$45 \%$

$100 \%$

Percentage
of Choices

$55 \%$

$1,385.5$

$1,385.5$

2,771

Weighted $f_{e}$

1440.92

$1,330.08$

2,771

\section{Analysis of Listening Task Per Quarter}

The judges' choices were counted per each quarter of the judges' task (Table VIII). For the total of 100 sentence pairs listened to, each successive quarter consisting of 25 sentences was totaled individually to determine the possible occurrence of "progression effects." It was previously described how the judges overall chose the "On" condition significantly more often than the "Off" condition. In Quarter I, Chi Square revealed no preference between "Aids On" and "Aids Off." In Quarter II, the numbers shifted to more choices for "Aids On," but still no statistically significant preference for either condition existed. Quarters III and IV's choices for "Aids On" were $61 \%$ and $62 \%$, respectively, which were the significant choices to the .01 level of confidence. 


\section{TABLE VIII}

COMPARISON OF JUDGES' CHOICES FOR "ON" VERSUS "OFF"

PER QUARTER OF LISTENING TASK

\begin{tabular}{lcccccc}
\hline Quarter & $\begin{array}{c}\text { Chose } \\
\text { "On" }\end{array}$ & $\begin{array}{l}\text { Chose } \\
\text { "Off" }\end{array}$ & $\begin{array}{l}\text { \% of } \\
\text { Choices } \\
\text { For "On" }\end{array}$ & $\begin{array}{l}\% \text { "On" } \\
\text { Sentences } \\
\text { Column 1 }\end{array}$ & $\begin{array}{l}\% \text { "On" } \\
\text { Sentences } \\
\text { Column 2 }\end{array}$ & $x^{2}$ \\
\hline I & 441 & 480 & $48 \%$ & $64 \%$ & $36 \%$ & 1.6515 \\
II & 469 & 479 & $49 \%$ & $56 \%$ & $44 \%$ & 0.1055 \\
III & 635 & 407 & $61 \%$ & $44 \%$ & $56 \%$ & 49.8887 \\
IV & 622 & 374 & $62 \%$ & $44 \%$ & $56 \%$ & 61.7510
\end{tabular}

Note: for significance to the .01 level of confidence, with 1 degree of freedom, $x^{2}$ must be greater than or equal to 6.63490

In addition to the progression to more "Aids On" choices, the percentages of "Aids On" in Quarters I and II shifted from less than $50 \%$ (36\% and $44 \%$ respectively) for the second sentence of each sentence pair, to greater than 50\% in Quarters III and IV $156 \%$ in each quarter).

There appeared to be a progression effect occurring from first quarter to last. The judges' choices during Quarters I and II were randomly distributed, relative to "Aids On," while their choices in Quarters III and IV indicated a significant preference for the "Aids On" condition. This shift in choices occurred simultaneously with the progression to a greater percentage of "Aids On" sentences in the second column, possibly indicating that the shift was due to the "repetition of utterance" effect. Since the judges consistently chose the second column significantly more often than the first, the 
progression to more "Aids On" choices in the second column would naturally lead to more total choices for "Aids On." This consistency of preference for the second sentence is displayed in Table IX.

TABLE IX

COMPARISON OF JUDGES' CHOICES FOR SENTENCE \#1 VERSUS

SENTENCE \#2 PER QUARTER OF LISTENING TASK

\begin{tabular}{lccc}
\hline Cuarter & $\begin{array}{c}\text { Chose } \\
\text { Sentence } \\
\# 1\end{array}$ & $\begin{array}{c}\text { Chose } \\
\text { Sentence } \\
\# 2\end{array}$ & $x^{2}$ \\
\hline I & 223 & 698 & 244.9783 \\
II & 287 & 661 & 147.5485 \\
II I & 341 & 701 & 124.3762 \\
IV & 285 & 711 & 182.2048 \\
\hline
\end{tabular}

Note: for significance to the .01 level of confidence, with 1 degree of freedom, $X^{2}$ must be greater than or equal to 6.63490

Reliability Test

The reliability test included a total of ten sentence pairs, one pair from each child, with the order reversed from the original presentations on the listening tape. Results of this retest indicated a reversal of preference from "Aids On" most intelligible to "Aids Off" most intelligible (Table $X)$. 
TABLE $X$

RELIABILITY TEST: ORIGINAL SENTENCES

VERSUS RETEST OF SAME SENTENCES

IN REVERSE ORDER

\begin{tabular}{lcccccc} 
& $\begin{array}{l}\text { Chose } \\
\text { Column }\end{array}$ & $\begin{array}{l}\text { Chose } \\
\text { Column } \\
2\end{array}$ & $\begin{array}{c}\text { Chose } \\
\text { "On" }\end{array}$ & $\begin{array}{c}\text { Chose "Off" } \\
\text { Column }\end{array}$ & $\begin{array}{c}\text { Column } \\
\text { Con" }\end{array}$ \\
\hline $\begin{array}{l}\text { Original } \\
\text { Sentences }\end{array}$ & 91 & 306 & 283 & 114 & $20 \%$ & $80 \%$ \\
$\begin{array}{l}\text { Reverse } \\
\text { Rever }\end{array}$ & 91 & 252 & 139 & 204 & $80 \%$ & $20 \%$ \\
\hline
\end{tabular}

During the retest the preference reversal from "Aids On" to "Aids Off" corresponded with the shift from more to less "Aids On" sentences in column 2 (Table $X$ ). When the sentences were originally preseted, $80 \%$ of the second sentences in each pair were "Aids On." Chi Square revealed that the judges significantly chose the second sentences as most intelligible, and also significantly chose "Aids On" as most intelligible (Table XI). When the sentences were reversed for the reliability test, this resulted in only $20 \%$ of the second sentences being "Aids On." The judges again chose the second sentences as most intelligible, consistent with the "repetition of utterance" effect noted earlier (see "Sentence \#1 Versus Sentence \#2 Comparison," p. 37 of this document), but their preference for the aided condition being most intelligible shifted to the unaided condition. 
TABLE XI

RESULTS OF CHI SQUARE ANALYSIS

OF RELIABILITY TEST

Comparison

$x^{2}$

Implication

Original sentences:

"Aids On" versus

"Aids Off"

Original sentences:

sentence \#1 versus

sentence \#2

Retest sentences:

"Aids On" versus

"Aids Off"

Retest sentences

sentence \#1 versus

sentence \#2
71.9421 Judges chose "Aids On" as "Most Intelligible" significantly more often than "Aids Off"

116.4358 Judges chose sentence \#2 as "Most Intelligible" significantly more often than sentence \#1

12.3178 Judges chose "Aids off" as "Most Intelligible" significantly more often than "Aids On"

75.5714 Judges chose sentence \#2 as

"Most Intelligible" significantly more often than sentence \#1

Note: for significance to the .01 level of confidence, with 1 degree of freedom, $x^{2}$ must be greater than or equal to 6.63490

\section{DISCUSSION}

Based on Chi Square analyses of 6,296 decisions, the judges perceived a difference, choosing "Aids On" as more intelligible than "Aids Off." Confounding variables, however, were: 1) the ever-present "repetition of utterance" effect; and 2) the reliability test which resulted in the judges' preference for the aided condition being most intelligible shifting to the unaided condition.

In total, Chi Square analyses were performed on eight different comparisons from the judges' results (Table XII). Three of these compared conditions between the two columns: 1) sentence \#1 versus sentence \#2;2) "Aids On" column 1 versus "Aids On" column 2; and 3) 
"Aids Off" column 1 versus "Aids Off" column 2. For each of these column-to-column comparisons, a significant "repetition of utterance" effect was detected, i.e., the choices were consistently skewed to the second column.

TABLE XII

OVERVIEW OF RESULTS OF ALL COMPARISONS

Comparison

$x^{2}$

Indication

Sentence \#1 versus

Sentence \#2

Sentence \#2 versus

"No Difference"

"Aids On" versus

"Aids Off"

"Aids Off"versus

"No Difference"

"Aids On"column 1 versus "Aids On" column 2

"Aids Off" column 1 versus"Aids Off" column 2

"Aids On" column 1 versus "Aids Off" column 1

"Aids On" column 2 versus "Aids Off" column 2
684.2142 Judges chose sentence \#2 as most intelligible

28.2798 Judges chose "No Difference" more often than sentence \#2

46. 6673 Judges chose "Aids On" as more intelligible than "Aids Off"

102.0104 Judges chose "No Difference" more of ten than "Aids Off"

338.9243 Judges chose "Aids On" column 2 more often than "Aids On" column 1

347.8644 Judges chose "Aids off" column 2 more often than "Aids Off" column 1

26.6514 Judges chose "Aids On" column 1 more often than "Aids Off" column 1

23.0996 Judges chose "Aids On" column 2 more often than "Aids Off" column 2

Note: for significance to the .0 level of confidence, with 1 degree of freedom, $X^{2}$ must be greater than or equal to 6.63490 
It should be noted at this point that the results were observed with respect to the ages of the children. It was important to know if there were any trends with respect to increasing age. Table I contains the ages of each child, while Appendix $G$ displays the judges' results for each individual child relative to "On" versus "Off" decisions. All that can be seen after examining the results is that none of the children above age 10.3 years were perceived as having greater intelligibility with "Hearing Aids On." There were three children above that age. The judges made no preference for two of these children, while preferring "Hearing Aids Off" as most intelligible for one of these older children (the one with the cochlear implant). It can also be seen in Appendix $H$ that the judges preferred sentence \#2 as most intelligible for all 10 of the speakers.

The results indicated that, disregarding all other factors, the second sentences sounded more intelligible to the judges. In "normal" verbal communication, a common strategy for a listener to clarify an unintelligible utterance is to request that the speaker repeat the statement (see "Repetition of Utterance," p. 24 of this document). Hearing what was said a second time may clarify a partially-understood message, and can even give meaning to a previously unintelligible utterance. Due to this inherent communication strategy, it seems reasonable to assume that this phenomenon was occurring when judges listened to sentences side-by-side, supporting Monsen's (1983) claim that "repetition of utterance" increases judges' ratings of speech intelligibility.

In spite of the "repetition of utterance" effect the data still 
indicated a perceived difference in intelligibility between the "On" and "Off" conditions. This supported the research hypothesis and would seem to support the claim of parents and teachers that the speech of these children does, in fact, deteriorate rather quickly when hearing aids are removed (Stone, 1987). The results were promising enough to warrant a replication of this aspect of the present study, controlling the "repetition of utterance" effect. 
CHAPTER V

CONCLUSION

SUMMARY

Results of this research endeavor indicated that inexperienced listening judges perceived the speech of deaf children as less intelligible with removal of amplification. This preference for the "Aided" condition occurred concurrently with a preference for the second sentence of each sentence pair as "Most Intelligible." The preference for the "Aided" condition was found when comparing the conditions within individual columns, meaning that when each column was analyzed individually, there were significantly more listener choices for the "Aided" than the "Unaided" conditions. This was one way to eliminate the "repetition of utterance" effect that strongly biased the listener choices to the second sentence of each sentence pair. The reliability test gave results that contradicted the preference for the "Aided" condition while supporting the preference for the second sentence of each sentence pair.

Since this would appear to be the first study comparing hearing-impaired children under the "Aids On" and "Aids Off" conditions, there was no previous research to indicate that the "repetition of utterance" effect would play such a significant role. This study dealt with subjective impressions by naive listeners, and each choice reflected a preference based on the criteria for "Most 
Intelligible" (Appendix D); thus, any absolute conclusions would be premature, regardiess of the strength of the data. There either was or was not a real difference in the speakers' intelligibility, and while the results of this study say there was, the confounding variables ("repetition of utterance" effect and reliability test) must be taken into account when interpreting the results.

\section{IMPLICATIONS}

Based on the outcomes of this study the following suggestions are offered for future investigations: 1) Correlate subjective impressions of listeners with acoustical characteristics of the speech of hearing-impaired persons; 2) Assess intelligibility using a "rating" system rather than adjacent sentence comparisons; 3 ) Reduce the "Hawthorne Effect;" and 4) Adhere to standardized means of assessing the intelligibility of the deaf.

While it was important to determine if 1 isteners would perceive intelligibility differences between the two sampled conditions, the logical next step would be to attempt to correlate these subjective impressions with the acoustical characteristics of the speech of hearing-impaired persons. This poses the question: "What are the objective acoustical speech parameters that are changing when listeners subjectively perceive changes in intelligibility?"

It was this investigator's original intention to measure selected acoustical parameters and look for correlations with the listener judgments of intelligibility differences. That phase of the study was abandoned, however, and it is hoped that the time and 
resources will become available to continue the effort. This document reflects those original intentions, and those portions of Chapter II above that deal with acoustical parameters of deaf speech were left intact partly as a resource for further efforts by this investigator, or others, in attempting to make this correlation (see "Correlation of Speech Errors and Intelligibility Judgments," p. 25). It is an area of research that has received relatively little attention. Monsen (1978), however, has notably compared acoustic characteristics of deaf speech with independently determined intelligibility scores. His results add the objective dimension of acoustical analysis to an otherwise subjective task. Further studies looking for correlations would be useful to confirm or add to his results, and if such correlations do in fact exist, they could be applied as a cross-check to any study that uses listeners to make intelligibility judgments.

The "repetition of utterance" effect that resulted from side-by-side comparison of sentences must also be taken into account in any similar research endeavor. This investigator believes it is an inevitable consequence of the type of design used for this study, and should be altered to eliminate the effect. Since the design of this investigation used the judging paradigm of "more" or "less" intelligible, perhaps a future design could require ratings of intelligibility, as suggested by Monsen (1983).

In psychological research the "Hawthorne Effect" is known to contaminate test results when it occurs. This is the effect of the subject's awareness of the testing climate altering otherwise normal responses. In this study, the Hawthorne Effect may have occurred due 
to the subjects' awareness that they were participants in a study, and the specific nature of the instructions and conditions that were presented to them. These children were made conscious of the testing paradigm by: 1) informed consent letters sent to their parents; 2) informed consent letters that they read and signed; 3 ) relocation to a sound booth for speech samples; 4) speech sampling into a microphone with awareness of a "running" tape recorder; and 5) removal and placement of hearing aids at school during the first test day. The combined effects of these events made the children very aware of the fact that they were involved in a research study that was comparing their speech with hearing aids on against that with hearing aids off. It is likely that they were using their "best speech" during each speech sample, and this possibly may not have been representative of their "typical speech." During the sample with their hearing aids off, it can be assumed that any auditory feedback they had been getting from their hearing aids was effectively eliminated. Under this sampling condition, however, these children made a conscious effort to speak as clearly as they were able, and may have used tactile and kinesthetic (or other) cues for self-monitoring purposes to a greater extent than they may have under "normal" speaking conditions without their hearing aids. It can only be surmised how this effect may have affected their speech, but it is certainly a possibility worthy of consideration in any future efforts similar to this one. It is recommended by this investigator to attempt to eliminate as many of these "awareness factors" as possible to minimize the Hawthorne Effect. 
Due to the inconsistency in speech intelligibility measurements, a standardized means of assessing the intelligibility of the deaf has not been developed (Monsen, 1983). In spite of its obvious importance in assessing the progress of deaf children learning speech, these children usually do not receive an evaluation of their intelligibility other than subjective individual evaluation of speech performance.

Due to the lack of agreement among deaf educators regarding the proper means of teaching speech to the deaf, a standardized measure of speech performance is necessary in order to validate claims of one teaching method over another (Monsen, 1983). This does not exist and, therefore, claims are made based on individual data that cannot be compared. This confounds the decision-making process, by parents and educators alike, for any hearing-impaired child regarding educational placement.

Monsen (1983) determined that to standardize measurements of intelligibility of hearing-impaired persons, the following guidelines should be adhered to: 1) Sentences should be balanced for phonologic, linguistic, and syntactic complexity; 2) Listeners should be divided between equal numbers of experienced and inexperienced listeners; 3 ) Sentences should be spoken out of context; 4) Sentences should be presented auditory-onty; 5) Include simple sentences for speech samples to optimize the potential for intelligibility among speakers who might be considered unintelligible when producing more complex sentences; 6) Include sentences with normally complex parameters of phonology, language, and syntax, so as to allow assessment of 
intelligibility of "normal speech;" and 7) Allow for scoring of intelligibility judgments in such a way as to provide a quantitative measure of intelligibility (such as scoring each word independently). Monsen's suggestions for standardization of speech intelligibility measurements present an excellent guide for future research in this area. They appear to be more specifically related to ratings of intelligibility rather than side-by-side comparisons as made in this study. It is recommended by this investigator that ratings of intelligibility be utilized in future research with close adherence to this guide as a means of standardization across studies.

\section{CONCLUSION}

While the results from this study were significant, they must be interpreted conservatively. The judges' preference for the "Aided" condition was statistically conclusive, but the confounding test results must be integrated into the interpretation. If the "Aided" sentences were not, in fact, more intelligible, this question exists: Why did the judges find the speech more intelligible with amplification than without, in spite of their preference for the second sentences? This question opens the door for further research to provide a definitive answer to the original question, and it is hoped that new designs will be created and implemented to more fully understand the role of hearing aids relative to the speech of hearingimpaired children. 


\section{REFERENCES}

Angelocci, A.A. (1962). Some observations on the speech of the deaf. Vol ta Review, 64, 403-405.

Angelocci, A.A., Kopp, G.A., \& Holbrook, A. (1964). The vowel formants of deaf and normal-hearing eleven-to fourteen-year-old boys. Journal of Speech and Hearing Disorders, 29, 156-170.

Black, J.W. ( 1971). Speech pathology for the deaf. In Connor, L.E. (Ed.), Speech for the Deaf Child: Knowledge and Use. Washington, D.C.: A.G. Bell Association for the Deaf, pp. 154-169.

Bornstein, H. (1979). Systems of sign. In Bradford, L, \& Hardy, W. (Eds.), Hearing and Hearing Impairment (pp. 155-172). New York, New York: Grune \& Stratton, Inc.

Brannon, J.B., Jr. (1964). Visual feedback of glossal motions and its infiuence on the speech of deaf children. Northwestern University.

Castle, D.L. (1970). "Misinformation" among advocates of non-oral methodologies. American Annals of the Deaf, 115 (7):666-7.

DiCarlo, L.M. (1960). The effect of hearing one's own voice among children with impaired hearing. In A. Ewing (Ed.), The Modern Educational Treatment of Deafness. Manchester: Manchester University Press.

Goff, S.M. (1974). The effect of auditory feedback on the vocalizations of hearing-impaired children. Proceedings of the XVIth International Congress of Logopedics and Phoniatrics, Interlaken, Switzerland, pp. 132-134.

Hudgins, C.V. (1960). The development of communication skills among profoundly deaf children in an auditory training programme. In A. Ewing (Ed.), Modern Educational Treatment of Deafness. Manchester: Manchester University Press.

Hudgins, C.V., \& Numbers, F.C. (1942). An investigation of the intelligibility of the speech of the deaf. Genetic Psychological Monographs, 25, 289-392.

Jensema, C.J., Karchmer, M.A., \& Trybus, R.J. (1978). The rated speech intelligibility of hearing-impaired children: Basic relationships and a detailed analysis. Washington, DC: Office of Demographic Studies, Gallaudet College (Series R, No. 6). 
John, J.E.J., and Howarth, J.N. (1965). The effect of time distortions on the intelligibility of deaf children's speech. Language Speech, 8, 127-134.

Klopping, H.W.E. (1972). Language understanding of deaf students under three auditory-visual stimulus conditions. American Annals of the Deaf, 117: 389-396.

Knauf, V.H. (1972). Meeting speech and language needs for the hearing impaired. In Katz, J. (Ed.), Handbook of Clinical Audiology, Baltimore, MD: Williams \& Wilkins.

Krantz, M. (1985). Parent-infant programs for the hearing impaired. In Katz, J. (Ed.), Handbook of Clinical Audiology. Baltimore, MD.: Williams \& Wilkins.

Kyle, J.G. (1977). Audiometric analysis as a predictor of speech intelligibility. British Journal of Audiology, 11, 51-58.

Ling, D.E. (1976). Speech and the Hearing-Impaired Child: Theory and Practice. Washington, D.C.: The A.G. Bell Association for the Deaf, Inc.

Linton, M. \& Gallo, P.S. Jr. (1975). The Practical Statistician: Simplified Handbook of Statistics. Monterey, CA: Brooks/Cole Publishing to.

Ludvigsen, C. (1980). Acoustic aspects of auditory training with and without hearing aid. Scandinavian Audiology, Supplement 10, 69-83.

Maassen, B. \& Povel, D.J. (1985). The effect of segmental and suprasegmental corrections on the intelligibility of deaf speech. Journal of the Acoustical Society of America, 78, 877-886.

Markides, A. (1970). The speech of deaf and partially hearing children with special reference to factors affecting intelligibility. British Journal of Disorders of Communication, $5,126-140$.

Menyuk, P (1971). The Acquisition and Development of Language. Englewood $\mathrm{Cl}$ iffs, NJ: Prentice-haT,, Inc.

Mindel, E.D., \& Vernon, M. (1971). They Grow in Silence. Silver Spring, MD.: National Association of the Deaf.

Monsen, R.B. (1978). Improvement in vowel articulation of deaf children. Journal of Communication Disorders, $11,417-424$. 
Monsen, R.B. (1983). The oral speech intelligibility of hearing-impaired talkers. Journal of Speech and Hearing Disorders, 48, 286-296.

Montgomery, G.W.G. (1966). The relationship of oral skills to manual communication in profoundly deaf students. American Annals of the Deaf, 111 : 557-565.

Myklebust, H.R. (1964). The Psychology of Deafness. New York, New York: Grune \& Stratton.

Northcott, W.H. (1973). The Hearing-Impaired Child in a Regular Classroom: PreschooT, Elementary, and Secondary Years. Washington, D.C.: A.G. Bell Association for the Deaf.

Northern, J.L. \& Downs, M.P. (1984). Hearing in Children. Baltimore, MD: Waverly Press, Inc.

Nowe11, R.C. (1985). Psychology of hearing impairment. In Katz, J. (Ed.), Handbook of Clinical Audiology. Baltimore, MD.: Williams \& Wilkins.

Pickett, J. (1968). Sound patterns of English: An Introductory Sketch. American Annals of the Deaf, 113, 120-126.

Schow, R. \& Nerbonne, M. (1980). Introduction to Aural Rehabilitation. Baltimore, Maryland: University Park Press.

Scouten, E.L. (1969). The prelingual deaf child and his oral education in a new perspective. American Annals of the Deaf, 114 (4): 770-776.

Siege1, G.M., \& Pick, H.L. (1974). Auditory feedback in the regulation of voice. Journal of the Acoustical Society of America, 56, 1618-1624.

Silverman, S.R., \& Lane, H.S. (1970). Deaf Children. In Davis, H. \& Silverman, S.R. (Eds.) Hearing and Deafness. New York, New York: Holt, Rinehart and Winston.

Smith, C.R. (1973). Residual hearing and speech production in deaf children. CUNY Communication Sciences Laboratory Research Report, \#4.

Smith, C.R. (1975). Residual hearing and speech production in deaf children. Journal of Speech and Hearing Research, 18, 795-811.

Stone, P. (1987). Director: Tucker-Maxon Oral School. Private communication. Portland, OR. 
Tannahill, J.C. \& Smoski, W.J. (1985). Overview of aural

rehabilitation. In Katz, J. (Ed.), Handbook of Clinical

Audiology. Baltimore, MD.: Williams \&Wilkins.

Thomas, W. (1964). Intelligibility of the speech of deaf children. Paper presented to the Convention of American Instructors of the Deaf, Washington, D.C.

Van Riper, C., \& Irwin, J. (1958). Voice and Articulation. Englewood Cliffs, N.J.: Prentice-Hal1.

Wansink, M., \& Povel, D.J. (1986). A computer-controlled vowel corrector for the hearing impaired. Journal of Speech and Hearing Research, 29, 99-105.

Yantis, P.A. (1985). Puretone air-conduction testing. In Katz, J. (Ed.), Handbook of Clinical Audiology. Baltimore, MD.: Williams \& Wilkins. 
APPENDIX A

\section{CID EVERYDAY SENTENCES, LIST B}

1. The water's too cold for swimming.

2. Why should I get up so early in the morning?

3. Here are your shoes.

4. It's raining.

5. Where are you going?

6. Come here when I call you!

7. Don't try to get out of it this time!

8. Should we let little children go to the movies by themselves?

9. There isn't enough paint to finish the room.

10. Do you want an egg for breakfast? 


\section{APPENDIX B}

\section{CID EVERYDAY SENTENCES, ALTERNATE SENTENCES}

1. Good morning.

2. Here we go.

3. Move out of the way!

4. Don't let the dog out of the house:

5. It's time to go.

6. I'll carry the package for you.

7. Be careful not to break your glasses!

8. I'm sorry.

9. There's a big piece of cake left over from dinner.

10. Children like candy. 
APPENDIX C

INSTRUMENTATION TECHNICAL DATA

MICROPHONE: Philmore Dynamic Cardioid

Model DC 93 Dual Impedance

Frequency Response: 100-12,000 Hz.

Sensitivity: $-57 \mathrm{~dB} \mathrm{Hi},-75 \mathrm{~dB}$ Lo

Polar Pattern: Unidirectional Cardioid

TAPE DECK: Dual C 939

Flutter and wow (Weighted R.M.S.): less than $+0.05 \%$

Frequency response: 20-17,000 $\mathrm{Hz}$. (FeCr tape)

Distortion ( $\mathrm{K} 3$ at $333 \mathrm{~Hz}$.; ref. to $0 \mathrm{~dB} \mathrm{VU}$ ): less than $1.0 \%$ (FeCr tape)

Signal-to-noise ratio (weighted): greater than $65 \mathrm{~dB}$ with Dolby $\mathrm{NR}$ ( $\mathrm{FeCr}$ tape)

TAPE DECK: Teac 7030SL

Wow and flutter: $0.04 \%$ at 15 ips

Frequency response: $25-26,000 \mathrm{~Hz}$. at 15 ips

Signal-to-noise ratio: $60 \mathrm{~dB}$

Harmonic distortion: $1 \%$ at $1,000 \mathrm{~Hz}$ normal operating leve 1 


\section{APPENDIX D}

\section{TAPE-RECORDED INSTRUCTIONS TO LISTENING JUDGES}

On this tape you will hear the speech of children who are severely hearing impaired. Your job will be to make judgments regarding whether or not there are differences in intelligibility between specific sentences. Intelligibility is defined for this study as your perception of the clarity or understandability of each sentence.

You have before you a scoresheet on which you will indicate your choices. After each pair of sentences has been presented you will mark the box on your scoresheet that corresponds with your decision. You will hear each sentence spoken twice and then decide if one is more intelligible than the other, or whether there is no difference in intelligibility. This will be indicated by checking box number one if you feel sentence number one is most intelligible, box number two if you believe sentence number two is most intelligible, or box number three if you do not perceive any difference in intelligibility between the two sentences. Again, for the purposes of this study, intelligibility is defined as your perception of the clarity or understandability of each sentence.

If there is any confusion regarding your task please have the operator stop this tape and ask your questions now. If not, the task will now begin. 


\section{APPENDIX E}

SCORESHEET FOR LISTENING JUDGES

MOST

NO

Most

No

SENTENCE INTELLIGIBLE DIFFERENCE SENTENCE INTELLIGIBLE DIFFERENCE

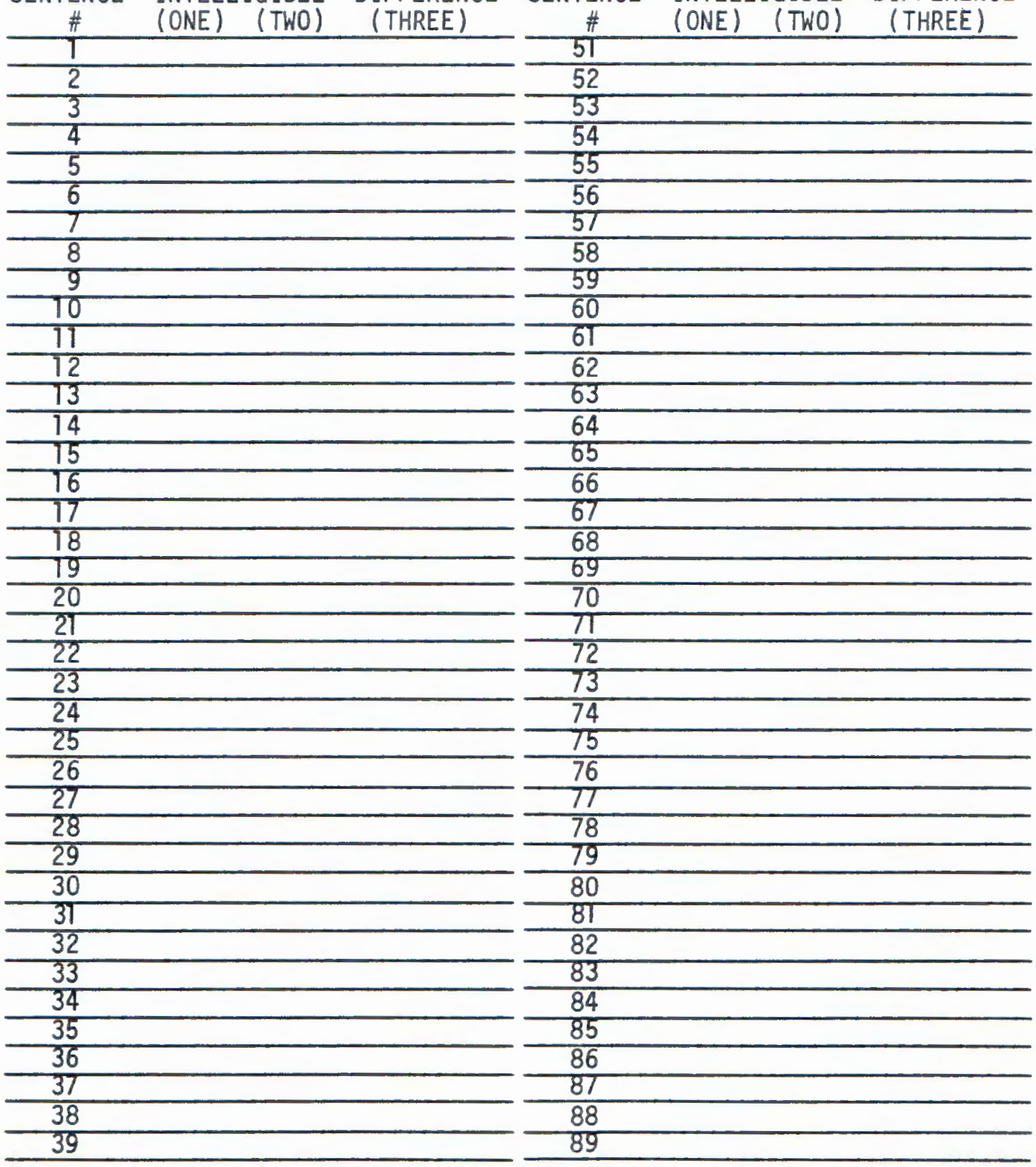




\begin{tabular}{ll}
$\frac{40}{41}$ & $\frac{90}{91}$ \\
\hline 42 & $\frac{92}{93}$ \\
\hline 43 & $\frac{93}{94}$ \\
\hline 44 & $\frac{95}{96}$ \\
\hline 45 & $\frac{96}{97}$ \\
\hline 46 & $\frac{98}{97}$ \\
\hline 48 & $\frac{99}{100}$ \\
\hline 49 & $\frac{100}{40}$ \\
\hline 50
\end{tabular}

\section{RELIABILITY TEST}

MOST

NO

Most

No

SENTENCE INTELLIGIBLE DIFFERENCE SENTENCE INTELLIGIBLE DIFFERENCE

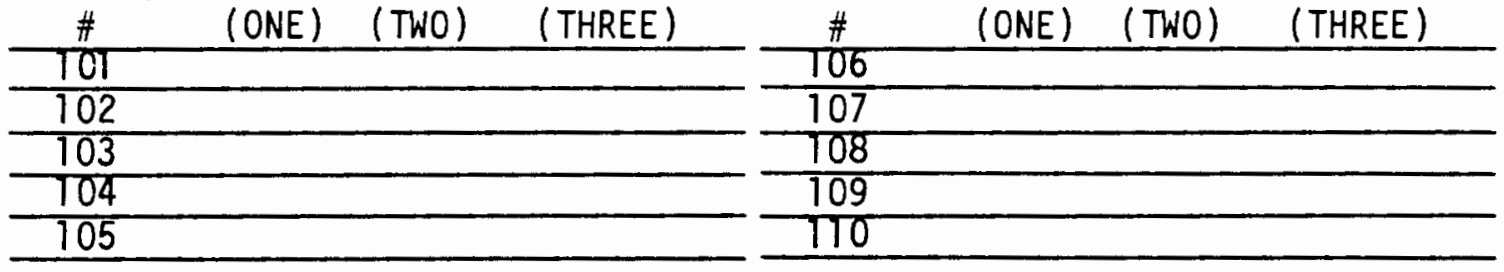




\section{APPENDIX F}

\section{RATIONALE FOR USE OF CHI SQUARE}

Once it was established that a significance test was necessary to analyze the data, four questions had to be answered to determine the type of statistical significance test to use: 1) type of dependent variable; 2) type of design (between-subjects, within-subjects, or mixed); 3) number of independent variables; and 4) number of levels for each independent variable (Linton \& Gallo, 1975).

Dependent Variable

The dependent variable usually results in one of three types of data: 1) score data; 2) frequency data; or 3) ordered data (Linton \& Gal10, 1975). Score data result when a subject's behavior or performance is assigned a numerical score. Ordered data result from ranking a subject on a dimension of interest. Frequency data result when a subject is placed in a certain category or cross-classification of categories. In this study each subject (1istening judge) made a choice for each sentence pair, resulting in each choice being placed into one of three sets of possible categories. The type of dependent variable, therefore, was frequency data.

\section{Type of Design}

The design of this study was a "within-subjects" design, meaning that all performance comparisons were made within the same group of subjects (hearing-impaired students) who were sampled under the two different conditions for each pair of sentences: 1) "hearing aids on;" and 2) "hearing aids off." 
Number of Independent Variables

A single independent variable was employed: use of hearing aids. In considering frequency data, however, it was simplest to regard all classification categories as independent variables (Linton \& Gallo, 1975). Each subject (1istener judge) was counted as being in a particular classification of categories for each sentence. There were three sets of categories: 1) "Hearing Aids On Most Intelligible;" 2) "Hearing Aids Off Most Intelligible;" and 3) "No Difference." For a test of significance, the frequency of occurrence (choices) of subjects (listening judges) in each category provides the data, with the number of subjects who fall into the different categories being counted.

Number of Levels for Each Independent Variable

While there was technically just one independent variable, each of the classification categories had just one level, i.e., there were not cross-classifications of categories.

Restrictions on the Use of Chi Square

The raw data for chi square must necessarily be frequencies. Chi square analysis is appropriate only when counting the number of subjects in particular classifications or cross-classifications Linton \& Gallo, 1975).

Chi square analyses require that each subject or event be counted only once or, technically, that all frequencies be independent (Linton \& Gal1o, 1975). This requirement might appear to rule out the use of chi square for within-subjects (repeated-measures) designs, since each 
subject would be counted more than once. Even if people are measured (two or more times, however, chi square may be used if the design can be arranged so that each subject is counted only once in the contingency table (and thus not violating the assumption of independence).

A value of chi square cannot be evaluated unless the number of degrees of freedom associated with it is known (Linton \& Gallo, 1975). The number of degrees of freedom associated with chi square was computed as follows: Since there was one independent variable: df $=(a-1)$, where $a$ is the number of levels of the independent variable.

Chi square was the significance test of choice for this study. While other significance tests may have been applied, chi square has the advantage of simplicity with enough flexibility to be adaptable to a variety of designs (Linton \& Gallo, 1975).

The researcher starts with a set of observed frequencies. Expected frequencies are determined either by some a priori expectations or on the assumption that the independent variables are not related. These expected frequencies represent the null hypothesis being tested. The more the observed frequencies differ from the expected frequencies, the less likely it is that the null hypothesis is true. (pp. 63-64) 
APPENDIX G

TABLE XIII

RESULTS OF INDIVIDUAL SUBJECTS IN ORDER

OF PRESENTATION ON LISTENING TAPE:

"AIDS ON" VERSUS "AIDS OFF"

\begin{tabular}{lllll}
\hline Subject \# $\begin{array}{c}\text { Chose } \\
\text { "Aids } \\
\text { On" }\end{array}$ & $\begin{array}{c}\text { Chose } \\
\text { "Aids } \\
\text { off" }\end{array}$ & $x^{2}$ & Indication \\
\hline 1 & 159 & 179 & 1.1834 & No preference \\
2 & 236 & 192 & 4.5234 & No preference \\
3 & 131 & 182 & 8.3099 & Chose "Aids Off" \\
4 & 163 & 279 & 30.4434 & Chose "Aids off" \\
5 & 221 & 127 & 25.3908 & Chose "Aids On" \\
6 & 295 & 124 & 69.7876 & Chose "Aids On" \\
7 & 205 & 193 & 0.3618 & No preference \\
8 & 257 & 200 & 7.1094 & Chose "Aids On" \\
9 & 263 & 140 & 37.5409 & Chose "Aids On" \\
10 & 237 & 124 & 35.3737 & Chose "Aids On" \\
\hline
\end{tabular}

Note: for significance to the .01 level of confidence, with 1 degree of freedom, $X^{2}$ must be greater than or equal to 6.63490 


\section{APPENDIX H}

TABLE XIV

RESULTS OF INDIVIDUAL SUBJECTS IN ORDER

OF PRESENTATION ON LISTENING TAPE:

SENTENCE \#1 VERSUS SENTENCE \#2

\begin{tabular}{lcccl}
\hline & $\begin{array}{c}\text { Chose } \\
\text { Sentence } \\
\# 1\end{array}$ & $\begin{array}{c}\text { Chose } \\
\text { Sentence } \\
\# 2\end{array}$ & $x^{2}$ & Indication \\
\hline 1 & 105 & 233 & 48.4734 & Chose sentence \#2 \\
2 & 94 & 334 & 134.5794 & Chose sentence \#2 \\
3 & 60 & 253 & 119.0064 & Chose sentence \#2 \\
4 & 127 & 315 & 79.9638 & Chose sentence \#2 \\
5 & 124 & 224 & 28.7356 & Chose sentence \#2 \\
6 & 129 & 290 & 61.8640 & Chose sentence \#2 \\
7 & 129 & 259 & 43.5567 & Chose sentence \#2 \\
8 & 124 & 333 & 95.5821 & Chose sentence \#2 \\
9 & 159 & 244 & 17.9280 & Chose sentence \#2 \\
10 & 75 & 286 & 123.3269 & Chose sentence \#2 \\
\hline
\end{tabular}

Note: for significance to the .01 level of confidence, with 1 degree of freedom, $X^{2}$ must be greater than or equal to 6.63490 


\section{APPENDIX I}

\section{INFORMED CONSENT LETTER: LISTENING JUDGES}

Dear Listening Judge:

I am a graduate student in Audiology at Portland State University. I am conducting a study, under the supervision of Jane Porter, M.S. and Robert English, Ph.D. regarding the speech of hearing-impaired children.

Your part in the study, as a judge, can be accomplished by the following: You will be asked to come to room 8, Neuberger Hall, at a time that is convenient for you. You will be seated along with other judges and your task will be explained. A tape recording of hearing-impaired children will be played and you will be asked to indicate which sentence of each pair of sentences is the most intelligible. You will mark each choice on a scoresheet which will be provided for you.

The judging session will last approximately 30 minutes. In no way will your name be used in reporting the results of this study. You may withdraw from your participation at any time.

If there are any questions or problems regarding any aspect of this study, I, or Jane Porter, may be reached at 229-3533. If you should experience problems as a result of your participation in this study, please contact Victor Dahl, Office of Graduate Studies and Research, 105 Neuberger Hall, Portland State University, 229-3423.

Due to the requirements of the Human Subjects Committee it is necessary that I obtain your informed consent prior to your participation in this study. I would like to ask your assistance in listening to these speech samples and making the appropriate judgments. Please indicate your willingness by signing below.

Thank you for your help.

Jim Henry

Portland State University Speech and Hearing Sciences 
YOUR NAME:

DATE:

ADDRESS:

PHONE:

DATE OF BIRTH:

MAJOR : LEVEL: 
APPENDIX J

INFORMED CONSENT LETTER: PARENTS OF SPEAKERS

February 23, 1987

Dear Parent(s):

I am a graduate student in Audiology at Portland State University, and also the parent of a student at Tucker-Maxon. I am conducting a study, under the supervision of Ms. Jane Porter and Dr. Robert English, regarding the speech of hearing-impaired children. I am attempting to determine if the speech of profoundly hearing-impaired children changes significantly when their hearing aids are removed. The results of this study should add to our knowledge about the effects of amplification for such children.

This study can be accomplished by the following: I will tape record a sample of your child's speech, with hearing aids on, during school in the morning. At the end of the school day your child will remove his/her aids and leave them at school where they will be secured for the night. The following morning at school I will tape record another speech sample of your child with hearing aids off. At this point your child's participation in the study will have been completed and she/he will be allowed to wear the hearing aids as usual. The aids will be electroacoustically analyzed in the meantime, along with an inspection of earmolds and tubing to assure proper functioning.

Each of the tapings will take approximately 15 minutes. You will be notified in advance of the exact dates of the speech sampling. In no way will your son/daughter's name be used in reporting the results of this study. You may withdraw from this study at any time.

If there are any questions or problems regarding any aspect of this study I may be reached at school at 229-3533. Additionally, Ms. Jane Porter may be reached at the same number. If you should experience problems as a result of your child's participation in this study, please contact Victor Dahl, Office of Graduate Studies and Research, 105 Neuberger Hal1, Portland State University, 229-3423.

Please sign below indicating your approval. If you are interested in the results please indicate below and I will send an abstract of the results of the study. This will require approximately 
6 months from the time the speech samples are taken. Thank you for your help.

Jim Henry

Portland State University

Speech and Hearing Sciences

SIGNATURE:

DATE:

CHILD'S NAME:

BIRTHDATE :

ADDRESS: 


\section{APPENDIX K}

\section{INFORMED CONSENT LETTER: SPEAKERS}

My name is - Jim Henry has asked me to help him finish a project at his school where he is studying to be an audiologist. My part in the project is to speak into a microphone two different times. He will give me a list of sentences and I will read them. The first day I will read them with my hearing aids on. At the end of that day at school I will take off my hearing aids and leave them with him to keep at school all night. The next morning at school I will read a list of sentences with my hearing aids off. When I have done that I will get my hearing aids back and put them on as I always do. I will then be finished with my part in the project.

I know that when I leave school the one afternoon without my hearing aids, it will be more difficult for me to talk to people. Jim Henry has told me it is important for his project that I go without my hearing aids from the time I leave school until the next morning.

My part in the projects may help other hearing-impaired children, and that is why the project is being done.

If I decide not to be a part of this project, it will not change anything at school for me. If I don't do it nobody will be mad at me and my grades will not be any different.

Jim Henry has told me he will help me if I don't understand or have any questions about his project. I know that if I change my mind and do not want to finish my part in the project I can stop at any time.

I am signing my name below to tell Jim Henry that I will help him finish his project, and that I understand everything that is said in this letter. 